\title{
Low-Valence Anionic $\alpha$-Diimine Iron Complexes: Synthesis, Characterization, and Catalytic Hydroboration Studies
}

\author{
Thomas M. Maier, Martin Gawron, Peter Coburger, Michael Bodensteiner, Robert Wolf,* \\ Nicolaas P. van Leest, Bas de Bruin, Serhiy Demeshko, and Franc Meyer
}

Cite This: Inorg. Chem. 2020, 59, 16035-16052

Read Online

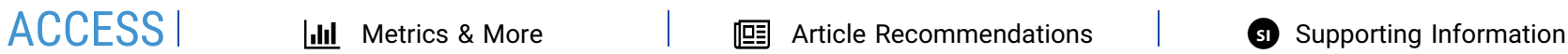

ABSTRACT: The synthesis of rare anionic heteroleptic and homoleptic $\alpha$-diimine iron complexes is described. Heteroleptic BIAN (bis(aryl)iminoacenaphthene) complexes 1-[K([18]c-6)(thf $\left.)_{0.5}\right]$ and $2-\left[\mathrm{K}([18] \mathrm{c}-6)(\text { thf })_{2}\right]$ were synthesized by reduction of the $\left[(\mathrm{BIAN}) \mathrm{FeBr}_{2}\right]$ precursor complex using stoichiometric amounts of potassium graphite in the presence of the corresponding olefin. The electronic structure of these paramagnetic species was investigated by numerous spectroscopic analyses (NMR, EPR, ${ }^{57} \mathrm{Fe}$ Mössbauer, UV-vis), magnetic measurements (Evans NMR method, SQUID), and theoretical techniques (DFT, CASSCF). Whereas anion $\mathbf{1}$ is a low-spin complex, anion 2 consists of an intermediate-spin $\mathrm{Fe}$ (III) center. Both complexes are efficient precatalysts for the hydroboration of

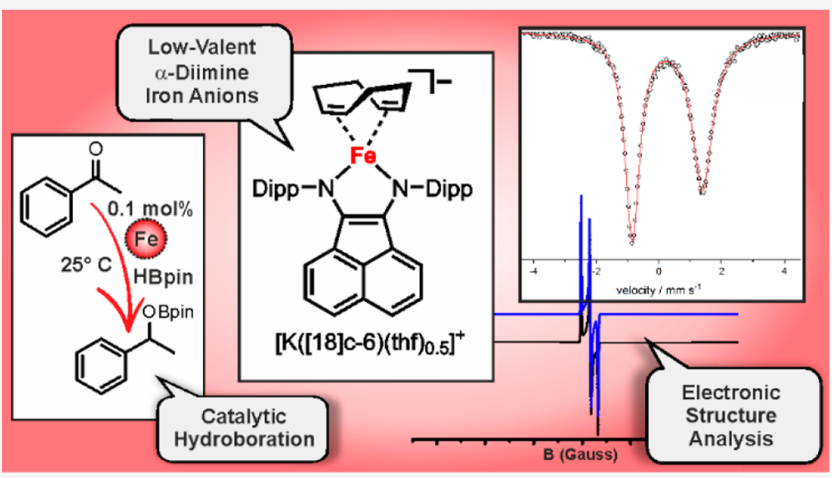
carbonyl compounds under mild reaction conditions. The reaction of bis(anthracene) ferrate(1-) gave the homoleptic BIAN complex 3-[K([18]c-6)(thf)], which is less catalytically active. The electronic structure was elucidated with the same techniques as described for complexes 1- $\left[\mathrm{K}([18] \mathrm{c}-6)(\text { thf })_{0.5}\right]$ and $2-\left[\mathrm{K}([18] \mathrm{c}-6)(\text { thf })_{2}\right]$ and revealed an $\mathrm{Fe}(\mathrm{II})$ species in a quartet ground state.

\section{INTRODUCTION}

Organometallic and coordination chemistry can contribute to a sustainable future by supporting the development of efficient catalysts based on earth-abundant metals. ${ }^{1}$ One key objective in these areas is the development of first-row transition metal compounds that replace precious metals in existing reactions or potentially even mediate entirely new reactions, which are not yet accessible. Iron is the most earth-abundant transition metal, and it is a pivotal element for catalysis because it is cheap and shows a high synthetic versatility due to its formal oxidation states ranging from -2 to +6 . Meanwhile, some of the most important classes of large-scale chemical reactions are catalytic reductions (hydrogenations, hydroborations, and hydrosilylations) which play crucial roles in the synthesis of numerous fine chemicals, agrochemicals, fragrances, and food additives. $^{2}$ In this context, low-valence highly reducing iron species unsurprisingly became compounds of special interest, which can be used as efficient catalysts. ${ }^{3}$

Metal-mediated catalytic cycles typically consist of elementary two-electron processes such as oxidative addition or reductive elimination. Precious metals such as rhodium $[\mathrm{Rh}(\mathrm{I}) / \mathrm{Rh}(\mathrm{III})]$ or palladium $[\mathrm{Pd}(0) / \mathrm{Pd}(\mathrm{II})]$ easily undergo such redox reactions and hence are typically favored from this point of view. In contrast, for first-row transition metal complexes, one-electron reactions are often observed. The concept of using redox-active ligands was introduced for first- row transition metal catalysis to gain control over the often very reactive intermediates and to mimic the behavior of precious metals. ${ }^{4}$ A redox-active ligand is capable of storing and releasing electrons and can therefore be directly involved in catalytic reactions by facilitating net $2 \mathrm{e}^{-}$processes that would otherwise be disfavored. ${ }^{5}$ A prominent class of redoxactive ligands is the $\alpha$-diimine family, members of which are almost always good $\pi$-acceptors and so well able to stabilize electron-rich metal centers. There are many examples of such transition-metal $\alpha$-diimine complexes known, in particular 3d metals such as nickel $^{6}$ or cobalt, ${ }^{7}$ which exhibit interesting catalytic properties. From a sustainibility point of view, especially low-valence iron complexes with redox-active $\alpha$ diimine ligands provide an attractive motif for applications in sustainable catalysis.

As a result, the synthesis of low-valence $\alpha$-diimine iron complexes bearing an unsaturated hydrocarbon as second ligand has attracted significant interest over the last two decades (Figure 1). ${ }^{8-20}$ In these complexes, the hydrocarbon is

Received: September 3, 2020

Published: October 20, 2020 
<smiles>[R]C1=C2C=CC([R])C2N([R])N1[R]</smiles>

Zenneck 1998 (A)

Chirik 2005 (B)

Song 2013 (C)

Findlater 2015 (D)

2017 (E)
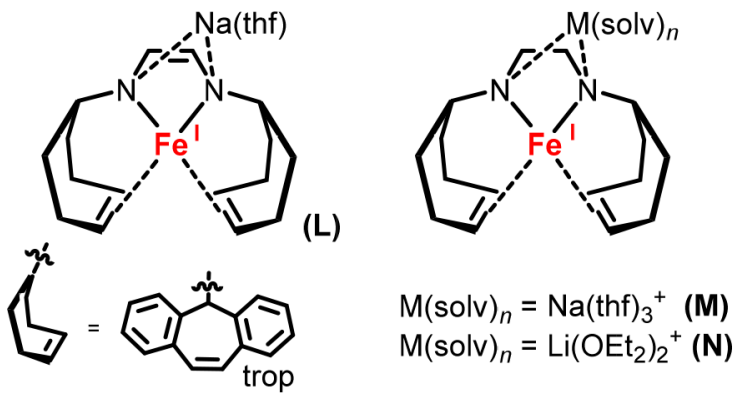

Lichtenberg, de Bruin, Grützmacher 2015

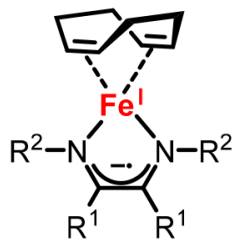

Chirik 2005 (F)

2018 (G)

Ritter 2016 (H)

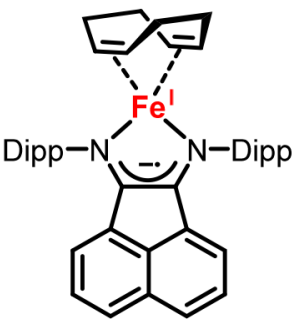

Findlater 2019 (I)

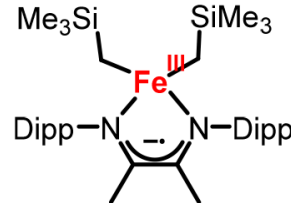

Chirik 2004 (J)

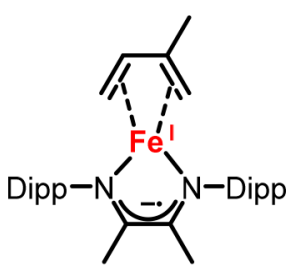

Chirik 2018 (K)

This work:

Highly-reduced heteroleptic $\alpha$-diimine ferrates

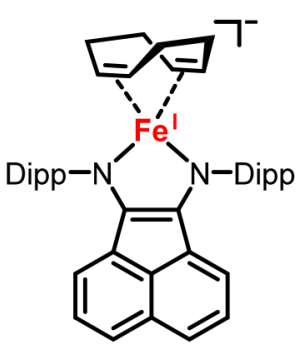

$1-\left[K([18] c-6)(\text { thf })_{0.5}\right]^{+}$

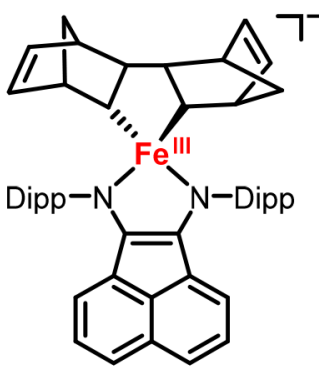

2- $\left[\mathrm{K}([18] \mathrm{c}-6)(\text { thf })_{2}\right]^{+}$

Figure 1. Previously reported low-valence $\alpha$-diimine iron complexes with hydrocarbon ligands, and the new complexes presented in this work. $\mathrm{R}=$ $\mathrm{H}, \mathrm{Me} ; \mathrm{R}^{1}=\mathrm{H},(\mathrm{A}-\mathrm{C}) \mathrm{Me},(\mathrm{D}, \mathrm{E}) \mathrm{BIAN} ; \mathrm{R}^{2}=$ aryl, alkyl; Dipp = 2,6-diisopropylphenyl; solv = solvent molecule.

supposed to act as a "placeholder", which is easily replaced by other substrates to initiate the catalytic cycle. These hydrocarbons are typically simple arenes as used for example in netneutral complexes $\mathbf{A}-\mathbf{E}$ shown in Figure 1 synthesized by the groups of Zenneck (A), ${ }^{8}$ Chirik (B) ${ }^{9}$ Song (C), ${ }^{10}$ and Findlater (D and E, all Figure 1). ${ }^{11,12}$ In these complexes, the $\mathrm{C}-\mathrm{C}$ bond of the $\alpha$-diimine unit is significantly shortened relative to the free ligand, whereas the $\mathrm{C}-\mathrm{N}$ bonds were stretched, which can be explained by an electron transfer from the metal center to the now formally anionic ligand. Of particular interest are the complexes $\mathbf{D}$ and $\mathbf{E}$ by Findlater and co-workers, who chose a bis(aryl)iminoacenaphthene (BIAN) ligand with a polyarene backbone instead of a simple $\alpha$-diimine ligand with a saturated backbone. ${ }^{11,12}$ BIAN ligands have been known since the 1960s and were established in coordination chemistry by Elsevier and co-workers. ${ }^{13,14}$ This ligand class benefits from a rigid backbone that ensures that the donor nitrogen atoms are fixed in the cis orientation that is required for metal coordination. Fedushkin and co-workers intensively studied the redox behavior of the DippBIAN (Dipp $=2,6$ diisopropylphenyl) ligand. Remarkably, it is possible to reduce DippBIAN to its tetraanionic state using sodium metal. ${ }^{15}$ However, such an extreme formal charge is rather unusual in transition metal complexes and usually neutral, monoanionic, or dianionic BIAN ligands are observed. Findlater and coworkers synthesized the $\left[\left({ }^{\text {Dipp }} \mathrm{BIAN}\right) \mathrm{Fe}(\right.$ arene $\left.)\right]$ (arene = benzene, toluene) complexes $\mathbf{D}$ and $\mathbf{E}$ by reduction of $\left[\left({ }^{\text {Dipp }} \mathrm{BIAN}\right) \mathrm{FeCl}_{2}\right]$ with $\mathrm{Na} / \mathrm{Hg}$ in the presence of the corresponding arene. The benzene complex acts as active precatalyst for the polymerization of L-lactide, whereas the toluene adduct can be used as a precatalyst in the hydrosilylation of ketones and aldehydes under solvent-free conditions. Metrical data taken from single-crystal X-ray crystallography support the hypothesis of a monoanionic $\alpha$ diimine ligand in those complexes. Independently, the group of Jacobi von Wangelin studied the hydrogenation of olefins mediated by an in situ catalyst formed from [( $\left.\left.{ }^{\text {Dipp }} \mathrm{BIAN}\right) \mathrm{FeCl}_{2}\right]$ and $n$-butyllithium in toluene. ${ }^{16}$

Chelating olefins such as 1,5-cyclooctadiene (cod) can also be used as labile hydrocarbon ligands. Such complexes have been reported by the groups of Chirik, Ritter, and Findlater. ${ }^{9,17,18}$ Chirik and co-workers synthesized the neutral tetrahedral iron complex F, which contains cod and an $\alpha$ diimine unit based on biacetyl..$^{9}$ This complex is an efficient precatalyst for the hydrogenation of simple olefins under mild conditions $\left(0.3 \mathrm{~mol} \%[\mathrm{Fe}], 4\right.$ bar $\mathrm{H}_{2}$, r.t. (r.t. $=$ room temperature)), although the formation of the catalytically inactive benzene complex $\mathbf{B}$ was observed for some styrenic substrates. Ritter and co-workers observed the catalytic dimerization of 1,3-butadiene to cod on a $>100 \mathrm{~g}$ scale using the similar complex $\mathbf{H} .{ }^{17}$ In the same report, the electronic structure of this complex was investigated with various techniques (SQUID magnetization measurements, ${ }^{57} \mathrm{Fe}$ Mössbauer spectroscopy, and DFT calculations), suggesting the presence of a high-spin $\mathrm{Fe}(\mathrm{I})(S=3 / 2)$ center, which is antiferromagnetically coupled to an $\alpha$-diimine radical anion. Findlater and co-workers introduced the BIAN ligand in this class of complexes, resulting in the formation of complex $\left[\left({ }^{\text {Dipp } B I A N)}\right) \mathrm{Fe}\left(\eta^{4}\right.\right.$-cod $\left.)\right](\mathrm{I}){ }^{18}$ The group of Chirik further contributed the neutral heteroleptic iron $\alpha$-diimine complexes $\mathbf{J}$ and $\mathbf{K}{ }^{19}$ Both complexes are coordinated by an $\alpha$-diimine ligand based on biacetyl with a ligand-sphere completed either by two $-\mathrm{CH}_{2} \mathrm{SiMe}_{3}$ ligands $(\mathrm{J})$ or by isoprene $(\mathbf{K})$.

In contrast to the research on neutral heteroleptic iron $\alpha$ diimine complexes, there are only three reports about anionic 
<smiles>[R]C1=C([R])N([R])[Z8]2(N1[R])N([R])C([R])=C([R])N2[R]</smiles>

tom Dieck 1977 (O)<smiles>[R]C1=C([R])N([R])[Z8]2(N1[R])N([R])C([R])=C([R])N2[R]</smiles>

Wieghardt 2008 (R)<smiles></smiles>

Walther $1982(\mathrm{P})$

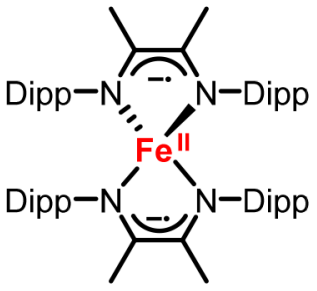

Chirik 2005 (Q)
This work: Highly-reduced homoleptic $\alpha$-diimine ferrates

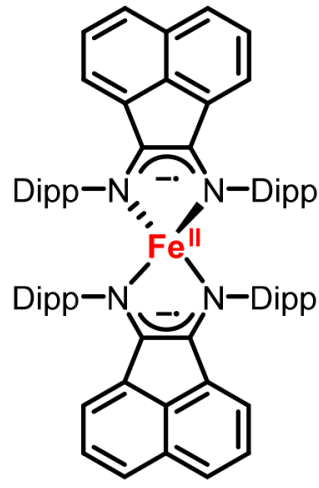

Fedushkin 2013 (S)

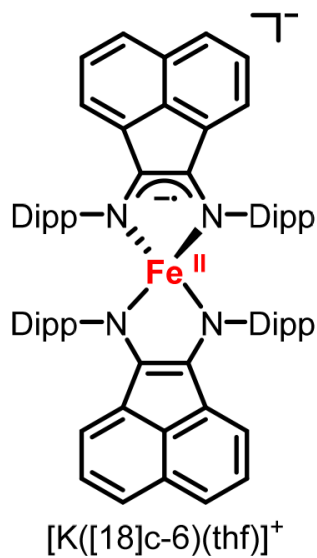

3

Figure 2. Previously reported homoleptic low-valence $\alpha$-diimine iron complexes and new anionic complexes presented in this work. $\mathrm{R}^{1}, \mathrm{R}^{2}, \mathrm{R}^{3}, \mathrm{R}^{4}=$ alkyl or aryl.

complexes, coming from the groups of Lichtenberg, de Bruin, and Grützmacher $(\mathbf{L}-\mathbf{N})$. In these complexes, the olefin and $\alpha$-diimine ligands were combined in one framework using a trop $_{2}$ dad ligand (trop $=5 H$-dibenzo $[a, d]$ cycloheptene-5-yl, dad $=$ diazadiene $).{ }^{20}$ The central iron atom of complex $\mathbf{L}$ adopts an almost square-planar geometry. The electronic structures of these complexes were studied by various experimental techniques and DFT calculations using the broken-symmetry approach. Single-crystal X-ray crystallography on the $\left[\mathrm{Na}(\text { thf })_{3}\right]^{+}$salt $\mathbf{L}$ suggested the presence of a dianionic diazadiene bound to $\mathrm{Fe}(\mathrm{I})$. The low-spin $\mathrm{d}^{7}$ electronic configuration was further confirmed by SQUID analysis, ${ }^{57} \mathrm{Fe}$ Mössbauer spectroscopy, and EPR studies. Analogous complexes $\mathbf{M}$ and $\mathbf{N}$ featuring a saturated backbone were also prepared and fully characterized. These complexes were used for the efficient dehydrogenation of dimethylamineborane and the dehydrogenative coupling of silanes and 1,4dibenzenemethanol.

Although there are several reports on heteroleptic $\alpha$-diimine complexes, the corresponding homoleptic counterparts remain scarce (Figure 2). ${ }^{9,21-24}$ These complexes have limited potential for applications in catalysis because of their limited capability to generate vacant coordination sites. Thus, such species have mainly served as subjects for electronic structure analysis. The group of tom Dieck synthesized the first lowvalent bis $(\alpha$-diimine $)$ iron species $\mathbf{O}$ by the reduction of bis $(\alpha$ diimine) iron(II) chloride salts with sodium metal. ${ }^{21}$ The $\alpha$ - diimines investigated were all 1,4-diaza-1,3-dienes derived from biacetyl and the resulting complexes were only analyzed by elemental analysis. Later on, Walther and co-workers investigated the chemistry of benzil dianil and electron-rich metal centers $\mathbf{P} .^{22}$ The iron complex was investigated by magnetic methods ( $\mu_{\text {eff }}=3.23 \mu_{\mathrm{B}}$ at r.t.), as well as spectroscopic techniques (IR, UV-vis). Chirik and co-workers synthesized the neutral bis $(\alpha$-diimine) iron complex $\mathbf{Q}$ by reduction of the corresponding $\alpha$-diimine iron(II) chloride precursor with $\mathrm{Na} / \mathrm{Hg}^{9}{ }^{9}$ This was the first compound of this type that was structurally characterized by single-crystal X-ray crystallography, revealing a tetrahedral geometry at iron. The metrical data, in particular the relatively long $\mathrm{C}-\mathrm{C}$ bond and short $\mathrm{C}-\mathrm{N}$ bond, in combination with magnetic susceptibility measurements, suggested a significant degree of $\alpha$-diimine ligand reduction. Wieghardt and co-workers subsequently provided a detailed analysis of the electronic structure of the species $\mathbf{R}$ by a combination of ${ }^{57} \mathrm{Fe}$ Mössbauer spectroscopy, magnetic susceptibility measurements, single-crystal X-ray crystallography, and density-functional theory using the broken-symmetry approach. ${ }^{23}$ It was concluded that the commonly used description of the electron structure with a central $\mathrm{Fe}(0)$ atom is in fact not correct. Instead, the complexes each contain two monoanionic $\alpha$-diimine ligands $(S=1 / 2)$ with a high-spin $\mathrm{Fe}(\mathrm{II})(S=2)$ center. Because of the antiferromagnetic coupling between the $\alpha$-diimine ligands and the iron atom, an overall spin of $S=1$ is observed for the 
Scheme 1. Synthesis of the Anion $\left[\left\{\left({ }^{\text {Dipp } B I A N) F e}\left(\eta^{4}-\operatorname{cod}\right)\right\}\right]^{-}(1)\right.$ by Reduction of an Fe(II) Precursor (Left) or Ligand Exchange Starting from an Fe(-II) Complex (Right)

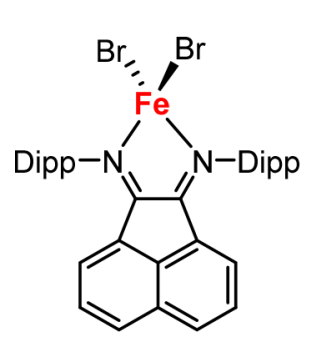

i) reduction

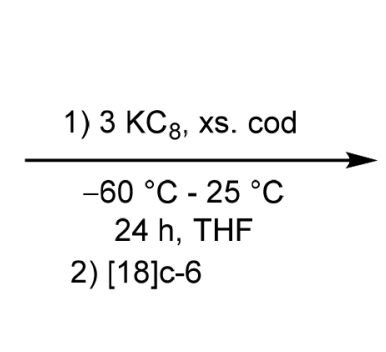

$1-\left[\mathrm{K}([18] \mathrm{C}-6)(\text { thf })_{0.5}\right]^{+}(78 \%)$
$1-[\mathrm{Li} \text { (thf) }]^{+}(55 \%)$

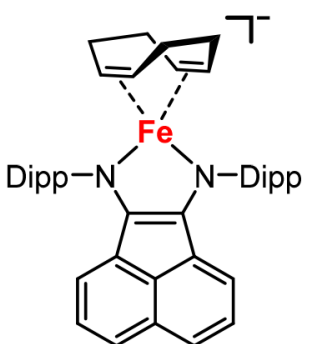

$1.5^{\text {Dipp }}$ BIAN

$-30{ }^{\circ} \mathrm{C}-25^{\circ} \mathrm{C}$

$24 \mathrm{~h}, \mathrm{THF}$

- LiBIAN

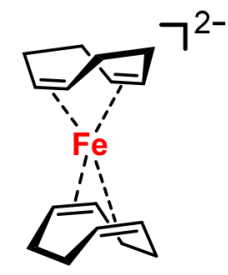

$2[\mathrm{Li}(\mathrm{dme})]^{+}$

ii) ligand exchange

Scheme 2. Synthesis of 2-[K([18]c-6)(thf $\left.)_{2}\right]$ by Reduction of $\left[\left({ }^{\mathrm{Dipp}} \mathrm{BIAN}\right) \mathrm{FeBr}_{2}\right]$ Using $\mathrm{KC}_{8}$ in the Presence of 2,5Norbornadiene

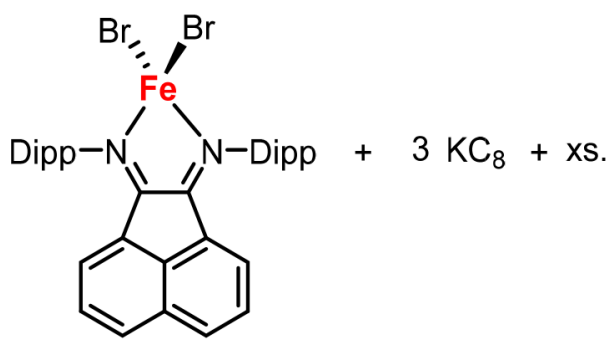<smiles>c1ccc2ccccc2c1</smiles>

1) $-60^{\circ} \mathrm{C}$ to $25^{\circ} \mathrm{C}$

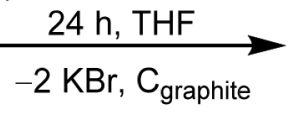

2) $[18] \mathrm{c}-6$

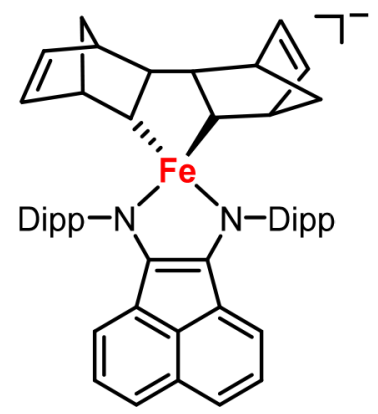

2-[K([18]c-6)(thf) $]^{+}$

$83 \%$ ground state. This work established the fact that $\alpha$-diimines are redox-active ligands. Later, a similar outcome was reported by Fedushkin and co-workers, who synthesized neutral $\left[\left({ }^{\text {Dipp }} \mathrm{BIAN}\right)_{2} \mathrm{Fe}\right](\mathbf{S})$ by the reaction of $\mathrm{K}\left[{ }^{\text {Dipp } B I A N]}\right.$ with $\mathrm{FeI}_{2}{ }^{24}$ The $\mathrm{C}-\mathrm{C}$ and $\mathrm{C}-\mathrm{N}$ bond lengths of the BIAN ligand have been very well investigated as a function of the oxidation state of the ligand. In the case of $\left[\left({ }^{D i p p} B I A N\right){ }_{2} \mathrm{Fe}\right]$, the structural data suggest the formation of a monoanionic ligand and consequently an $\mathrm{Fe}$ (II) center. Magnetic measurements and theoretical calculations also support the presence of antiferromagnetic coupling.

Recently, we reported amine-borane dehydrogenation and transfer hydrogenation catalyzed by the $\alpha$-diimine cobaltates $\left[\mathrm{K}(\mathrm{thf})_{x}\left\{\left({ }^{\mathrm{Ar}} \mathrm{BIAN}\right) \mathrm{Co}\left(\eta^{4}\right.\right.\right.$-cod $\left.\left.)\right\}\right][\mathrm{Ar}=$ Mes $(2,4,6$-trimethylphenyl), Dipp]. ${ }^{7 c, 25}$ This work showed that such highly reduced $\alpha$-diimine metal anions can be effectively used in reductive catalysis. This suggested that an analogous $\mathrm{Fe}$ complex should be a promising precatalyst for similar reactions. Herein, we report the synthesis, characterization, and catalytic applications of highly reduced anionic heteroleptic and homoleptic $\alpha$-diimine iron complexes.

\section{RESULTS AND DISCUSSION}

Synthesis of an Anionic $\alpha$-Diimine Fe Complex. As $\left[\mathrm{K}(\mathrm{thf})_{x}\left\{\left({ }^{\mathrm{Ar}} \mathrm{BIAN}\right) \mathrm{Co}\left(\eta^{4}-\mathrm{cod}\right)\right\}\right]$ is synthesized from the cobalt $(1-)$ source $\left[\mathrm{Co}\left(\eta^{4}-\mathrm{cod}\right)_{2}\right]^{-}$by simple ligand exchange, it was sought out to synthesize the analogous iron complex in the same manner starting from dianionic bis(cylooctadiene) ferrate $(2-)\left[\mathrm{Li}_{2}(\mathrm{dme})_{4}\left\{\mathrm{Fe}\left(\eta^{4}-\mathrm{cod}\right)_{2}\right\}\right]{ }^{26}$ Surprisingly, the

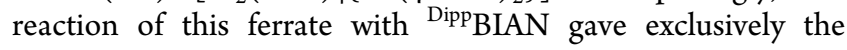

monoanionic complex $\left[\mathrm{Li}(\mathrm{thf})\left\{\left({ }^{\mathrm{Dipp}} \mathrm{BIAN}\right) \mathrm{Fe}\left(\eta^{4}-\mathrm{cod}\right)\right\}\right]$ (1$[\mathrm{Li}(\mathrm{thf})])$ and not the expected dianion. A plausible explanation for this observation is that LiBIAN is formed as a side product by an outer-sphere redox process, although this has not been confirmed experimentally. A ligand to metal [DippBIAN:Fe(2-)] ratio of $1.5: 1$ seemed to be ideal after optimization of the reaction conditions, although it is formally a 2:1 reaction (see the Supporting Information for details). Complex 1-[Li(thf)] was isolated as dark crystals after workup and crystallization from $n$-hexane in $55 \%$ yield $(41 \mathrm{mg}$ ) (see Scheme 1). Unfortunately, scale up of this reaction proved to be difficult. Therefore, a second approach involving reduction of the $\mathrm{Fe}(\mathrm{II})$ precursor $\left[\left({ }^{\mathrm{Dipp}} \mathrm{BIAN}\right) \mathrm{FeBr}_{2}\right]$ using strong reductants such as alkali metals was investigated. [( $\left.{ }^{\text {Dipp }} \mathrm{BIAN}\right)$ $\left.\mathrm{FeBr}_{2}\right]$ can be prepared in large scale $(>20 \mathrm{~g})$ in a single step from DippBIAN and $\mathrm{FeBr}_{2}$. Reduction of this complex using potassium graphite $\left(\mathrm{KC}_{8}, 3\right.$ equiv. $)$ in the presence of excess 1,5-cyclooctadiene was found to be more efficient than with

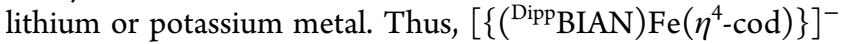
(1) was isolated as 1-[K([18]c-6)(thf $\left.)_{0.5}\right]$ in good yield $(78 \%)$ and at multigram scale $(>7 \mathrm{~g})$ after crystallization from THF/ $n$-hexane.

It is of further interest to investigate the influence of the bis(olefin) ligand with respect to the structure and reactivity. The replacement of the 1,5-cyclooctadiene (cod) ligand in our proposed ferrate precatalyst by 2,5-norbornadiene (nbd) was attempted. Therefore, the same reductive approach was pursued: reaction of $\left[\left({ }^{\mathrm{Dipp}} \mathrm{BIAN}\right) \mathrm{FeBr}_{2}\right]$ with potassium graphite and an excess of 2,5-norbornadiene followed by the addition of 18 -crown-6 $([18] \mathrm{c}-6)$ to facilitate crystallization 
Scheme 3. Synthesis of $3-[\mathrm{K}([18] \mathrm{c}-6)(\mathrm{thf})]$

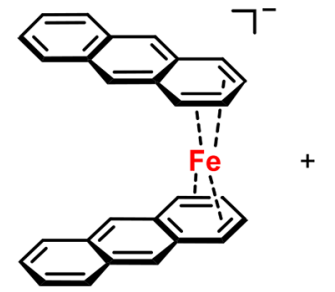

$\left[\mathrm{K}([18] \mathrm{c}-6)(\text { thf })_{2}\right]^{+}$
2<smiles>O=C(N=C1C(=NO)c2cccc3cccc1c23)c1ccccc1</smiles>

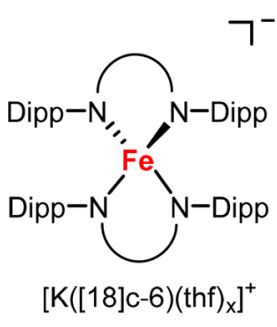

3-[K([18]c-6)(thf)]
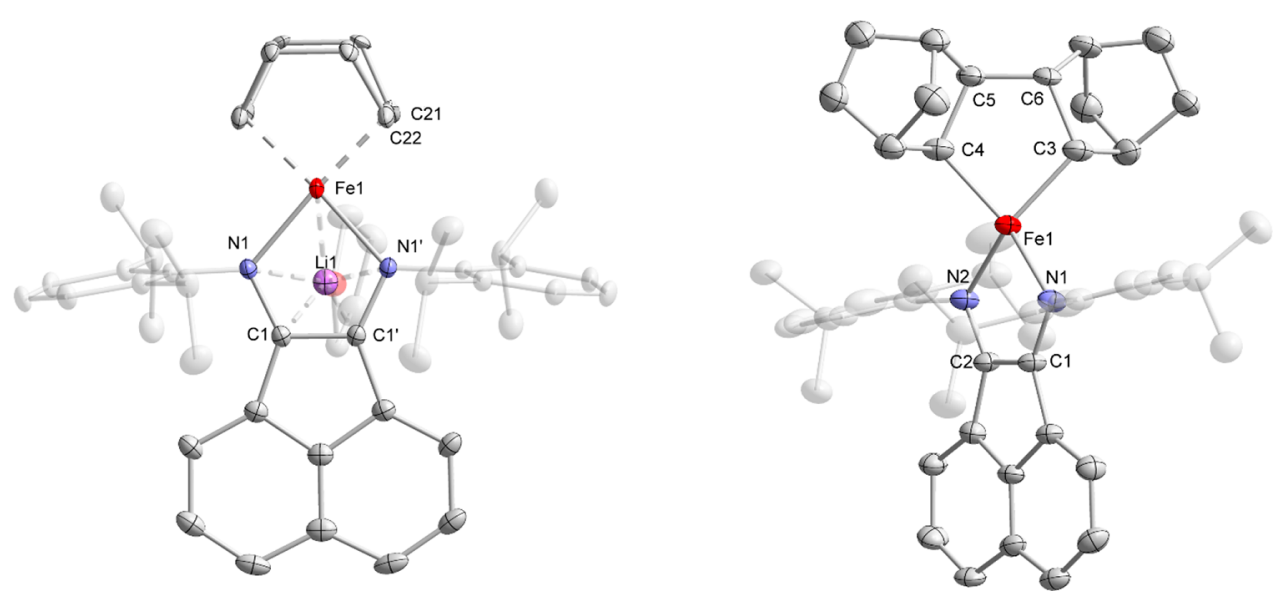

Figure 3. Solid-state structures of $1-[\mathrm{Li}(\mathrm{thf})]$ (left) and 2 -[K([2.2.2]cryptand)] (right) with thermal ellipsoids drawn at the $40 \%$ probability level. Selected bond lengths $(\AA)$ and angles (deg) are as follows. For 1-[Li(thf)]: N1-C1 1.385(4), C1-C1' 1.388(5), C21-C22 1.409(5), Fe1-N1

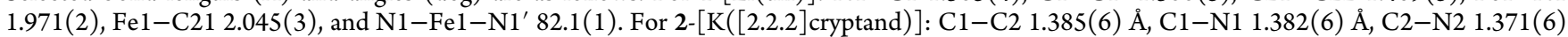

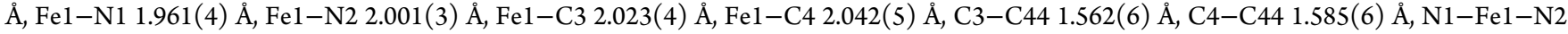
84.8(2), and C3-Fe-C4 86.7(2). Hydrogen atoms, solvent molecules (three THF molecules in the case of 2-[K([2.2.2]cryptand)]) and cation 2$[\mathrm{K}([2.2 .2] \text { cryptand })]^{+}$are omitted for clarity.

from THF/ $n$-hexane. Unexpectedly, a salt of the complex

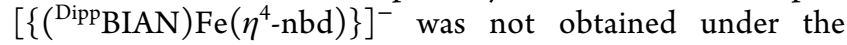
reaction conditions. Instead, single-crystal X-ray crystallography revealed that two norbornadiene ligands underwent $\mathrm{C}-$ $\mathrm{C}$ coupling to form a bis(norbornyl) ligand, resulting in a new complex 2-[K([18]c-6)(thf $\left.)_{2}\right]$, which was isolated in high yield (83\%) as deep-green crystals (Scheme 2).

For the synthesis of homoleptic anionic bis $(\alpha$-diimine $)$ iron complexes, the bis(anthracene) ferrate(1-) anion served as an available source for an iron anion. ${ }^{27}$ First, the reactivity of

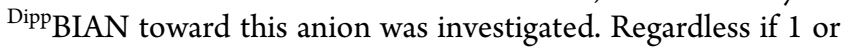
2 equiv. of the $\alpha$-diimine were added, only homoleptic and no heteroleptic complexes were isolated (Scheme 3). Thus, the replacement of both anthracene ligands furnished the homoleptic bis $\alpha$-diimine ferrate complex 3-[K([18]c-6)(thf)]. This complex is a rare example of an anionic bis $(\alpha$-diimine $)$ complex. ${ }^{28}$ Complex 3-[K([18]c-6)(thf)], was isolated in $46 \%$ crude yield and was recrystallized from THF/ $n$-hexane (sample $\left.3_{1^{-}}[\mathrm{K}([18] \mathrm{c}-6)(\mathrm{thf})]\right)$, resulting in $15 \%$ yield of isolated product. Another recrystallization of sample $3_{1^{-}}[\mathrm{K}([18] \mathrm{c}-$ $6)$ (thf)] gave sample $3_{2}-[K([18] \mathrm{c}-6)($ thf $)]$ in $7 \%$ yield. Sample $3_{1}-[\mathrm{K}([18] \mathrm{c}-6)(\mathrm{thf})]$ contains an unknown impurity, which can be removed by the second recrystallization. The characterization for sample $3_{1}-[\mathrm{K}([18] \mathrm{c}-6)(\mathrm{thf})]$ is described in the Supporting Information.

According to $\mathrm{CHN}$ analysis, sample $3_{1}-[\mathrm{K}([18] \mathrm{c}-6)(\mathrm{thf})]$ shows slight impurities as the carbon value does not perfectly match the calculated value for $3-[\mathrm{K}([18] \mathrm{c}-6)(\mathrm{thf})]$ bearing one THF molecule (calcd.: 73.77; found: 72.03), whereas the values for hydrogen (calcd., 7.88; found, 7.57) and nitrogen (calcd.: 3.91; found: 3.88 ) are close to the calculated values. For sample $3_{2}-[\mathrm{K}([18] \mathrm{c}-6)(\mathrm{thf})]$, the CHN calculated values are in reasonable agreement with the experimentally determined values (C 73.30, H 7.76, N 3.81).

Single-Crystal X-ray Crystallography. Complexes 1$\left[\mathrm{K}([18] \mathrm{c}-6)(\text { thf })_{0.5}\right]$ and $\mathbf{1}-[\mathrm{Li}($ thf $)]$ were structurally characterized by single-crystal X-ray crystallography. Unfortunately, the structure of $1-\left[\mathrm{K}([18] \mathrm{c}-6)(\text { thf })_{0.5}\right]$ was highly disordered and it was impossible to determine reliable bond distances. However, the connectivity and overall structure were confirmed. In contrast, the crystal structure of 1 -[Li(thf)] gave good values $\left(R_{1}=0.0383 ; w R_{2}=0.0929\right)$ and is shown in Figure 3. The complex crystallizes in the orthorhombic space group $P m n 2_{1}$ with two molecules per formula unit. The central iron atom $\mathrm{Fel}$ is coordinated in an almost perfect squareplanar environment (twist angle of $0.5^{\circ}$ ) by two nitrogen atoms and two $\mathrm{C}=\mathrm{C}$ double bonds. The elongated $\mathrm{C} 1-\mathrm{N} 1$ (1.385(4) $\AA$ ) and shortened $\mathrm{C} 1-\mathrm{Cl}^{\prime}$ (1.388(5) Å) bond lengths are in the range of dianionic BIAN ligands (cf. $1.40 \AA$ (C-C bond) and $1.39 \AA$ ( $\mathrm{C}-\mathrm{N}$ bond $)$ for $\left.\mathrm{Na}_{2}\left[{ }^{\text {Dipp }} \mathrm{BIAN}\right]\right){ }^{15}$ Consequently, an oxidation state of +1 with a $\mathrm{d}^{7}$ configuration for iron can be assigned. The lithium cation is $\eta^{4}$-coordinated to the dianionic moiety of the BIAN framework as well as by one THF molecule. Compound $1-[\mathrm{Li}(\mathrm{thf})]$ is therefore a 
contact-ion pair. It is worth noting that the recently published cobaltate $\left[\mathrm{Li}(\right.$ thf $\left.)\left\{\left({ }^{\text {Dipp }} \mathrm{BIAN}\right) \mathrm{Co}\left(\eta^{4}-\mathrm{cod}\right)\right\}\right]$ is isostructural to this compound. $^{7 \mathrm{c}}$

Although crystallographic analysis of $2-\left[\mathrm{K}([18] \mathrm{c}-6)(\mathrm{thf})_{2}\right]$ allowed determination of the connectivity of the ferrate anion, significant disorder prevented a more detailed structural analysis. Fortunately, the [2.2.2]cryptand complex 2-[K([2.2.2]cryptand)] prepared in an analogous manner provided a structure that could be refined to a much more satisfactory degree of accuracy. The complex crystallizes in the noncentrosymmetric space group $P 2_{1}$ with one molecule per asymmetric unit, which is shown in Figure 4. Here the central

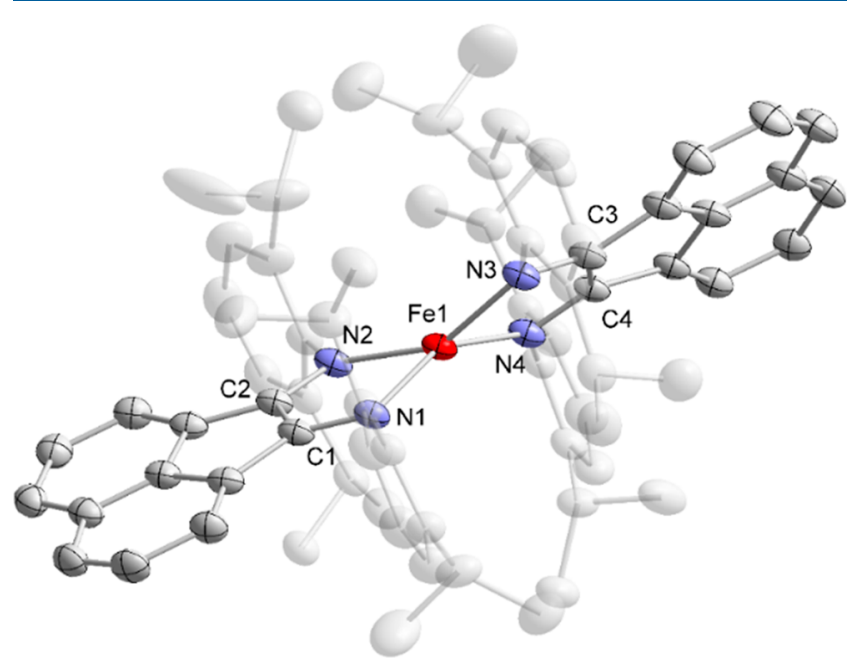

Figure 4. Solid-state structure of $3-[\mathrm{K}([18] \mathrm{c}-6)($ thf $)]$ with thermal ellipsoids drawn at the $40 \%$ probability level. Selected bond lengths (Å) and angles (deg): N1-C1 1.351(3), N2-C2 1.359(2), N3-C3 1.362(3), N4-C4 1.364(2), C1-C2 1.411(3), C3-C4 1.406(3), Fe1-N1 2.090(1), Fe1-N2 1.976(1), Fe1-N3 2.048(1), Fe1-N4 2.072(1), N1-Fe1-N2 81.58(1), and N3-Fe1-N4 82.56(6). Hydrogen atoms and $[\mathrm{K}([18] \mathrm{c}-6)(\text { thf })]^{+}$cation are omitted for clarity. iron atom $\mathrm{Fe} 1$ is coordinated by the two nitrogen atoms of BIAN (N1, N2) and two carbon atoms (C3, C4) of the bis(norbornyl) ligand in a distorted tetrahedral structure with a twist angle of $53.4^{\circ}$. Analysis of the $\mathrm{C}-\mathrm{C}(\mathrm{C} 1-\mathrm{C} 21.385(6)$ $\AA)$ and $\mathrm{C}-\mathrm{N}(\mathrm{C} 1-\mathrm{N} 1$ 1.382(6) $\AA, \mathrm{C} 2-\mathrm{N} 2$ 1.371(6) $\AA$ ) bonds indicated a dianionic BIAN ligand. ${ }^{15}$ In combination with the dianionic bis(norbornyl) ligand an oxidation state of +3 for iron can be assumed. Two molecules of norbornadiene have clearly dimerized through formation of a $\mathrm{C}-\mathrm{C}$ bond (olefin coupling) to give a bis(norbornyl) ligand and a fivemembered, perfectly planar ferracycle. Stereochemically, the ligand exists in an exo-trans-exo conformation. Such a norbornadiene dimerization at the metal center is rare and only known for three other systems, two based on iridium and one on zirconium. For the latter, Rosenthal and co-workers used a zirconocene alkyne complex as starting material and observed a twisted and not perfectly planar five-membered zirconacycle. $^{29}$ In 1980, Osborn, Fraser, and co-workers reported on an octahedral iridium complex bearing a dimerized norbornadiene ligand, one acetylacetonate ligand, and an additional single $\eta^{4}$-norbornadiene ligand. ${ }^{30}$ In there, the iridacycle is also nonplanar, being folded with one carbon atom displaced $0.24 \AA$ out of the plane of the ring atoms. Recently, Oro and co-workers also synthesized iridium complexes containing this structural motif. ${ }^{31}$ All are octahedral iridium complexes with five-membered, nonplanar iridacycles.

Crystals of $3-[\mathrm{K}([18] \mathrm{c}-6)(\mathrm{thf})]$ suitable for single-crystal Xray diffraction were obtained by slow diffusion of $n$-hexane into a THF solution. More than 10 crystals were examined. It is noteworthy that all of these had the same space group and cell parameters. A full single-crystal X-ray structure analysis on one of the crystals revealed that complex $3-[\mathrm{K}([18] \mathrm{c}-6)($ thf $)]$ crystallizes in the monoclinic space group $P 21 / n$ with four molecules of $3-[\mathrm{K}([18] \mathrm{c}-6)($ thf $)]$ per formula unit. The molecular structure is shown in Figure 4. There is no close interaction between the cation $\left[\mathrm{K}([18] \mathrm{c}-6)(\mathrm{thf})_{2}\right]^{+}$and the anion $\left[\left({ }^{\text {Dipp }} \mathrm{BIAN}\right)_{2} \mathrm{Fe}\right]^{-}$. The iron atom is coordinated via four nitrogen atoms. The dihedral angle between the two BIAN
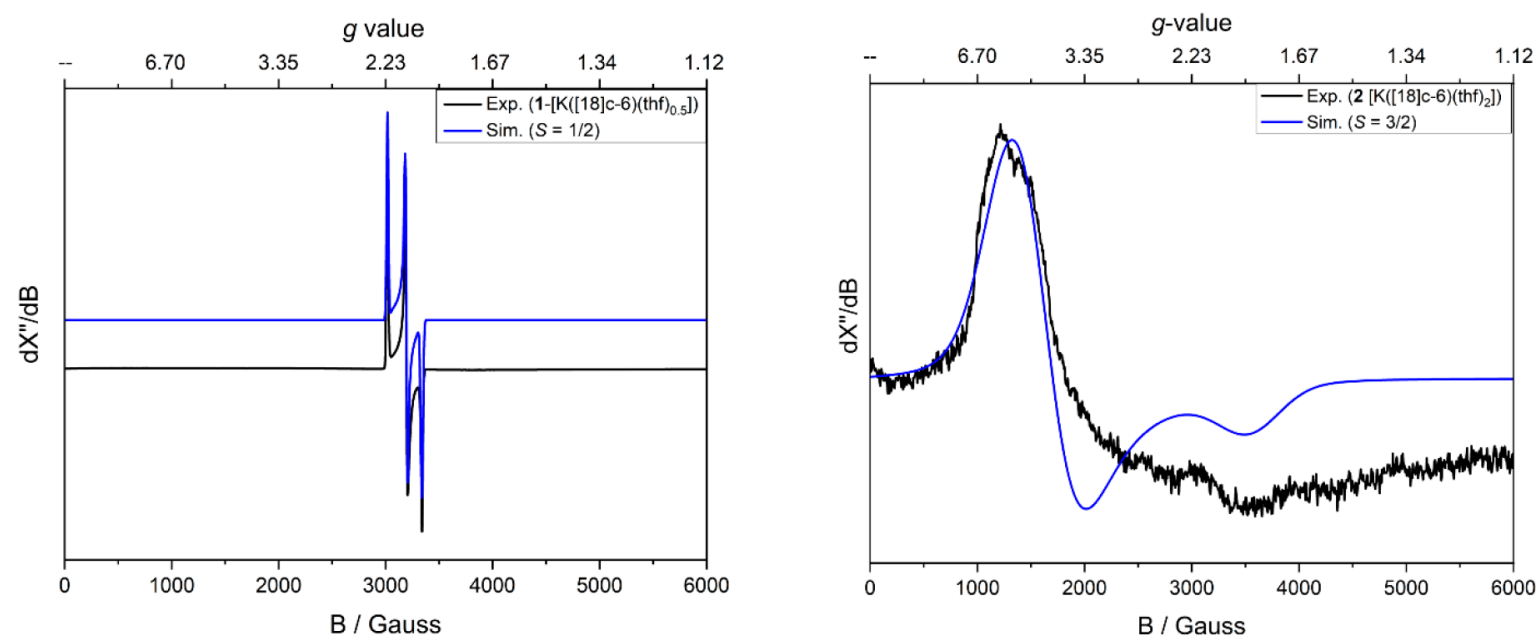

Figure 5. Experimental (Exp.) and simulated (Sim.) X-band EPR spectra of 1-[K([18]c-6)(thf) $\left.0_{0.5}\right]$ (left) and 2-[K([18]c-6)(thf) $\left.)_{2}\right]$ (right) recorded in a ${ }^{\mathrm{Me}} \mathrm{THF}$ glass at $20 \mathrm{~K}$. Experimental parameters: microwave frequency, $9.37466 \mathrm{GHz}\left(\mathbf{1}-\left[\mathrm{K}([18] \mathrm{c}-6)(\mathrm{thf})_{0.5}\right]\right)$ and $9.376835 \mathrm{GHz}(\mathbf{2}-$ $\left.\left[\mathrm{K}([18] \mathrm{c}-6)(\mathrm{thf})_{2}\right]\right)$; modulation amplitude, $4.000 \mathrm{G}$; power, $0.6325 \mathrm{~mW}$. The experimental spectrum of 1 - $\left[\mathrm{K}([18] \mathrm{c}-6)(\text { thf })_{0.5}\right]$ could be fitted with the following parameters for an $S=1 / 2$ system on a nucleus with a nuclear spin of 0 , which we attribute to iron. $g_{11}=2.20, g_{22}=2.10, g_{33}=$ 2.01, $W_{11}=10, W_{22}=11$, and $W_{33}=13$. The experimental spectrum of 2 - $\left[\mathrm{K}([18] \mathrm{c}-6)(\text { thf })_{2}\right]$ can be fitted using the following parameters for an $S=$ $3 / 2$ system. $g_{11}=2.25, g_{22}=2.25, g_{33}=1.90, D=15 \mathrm{~cm}^{-1}, E=0.8 \mathrm{~cm}^{-1}, E / D=0.05$. 


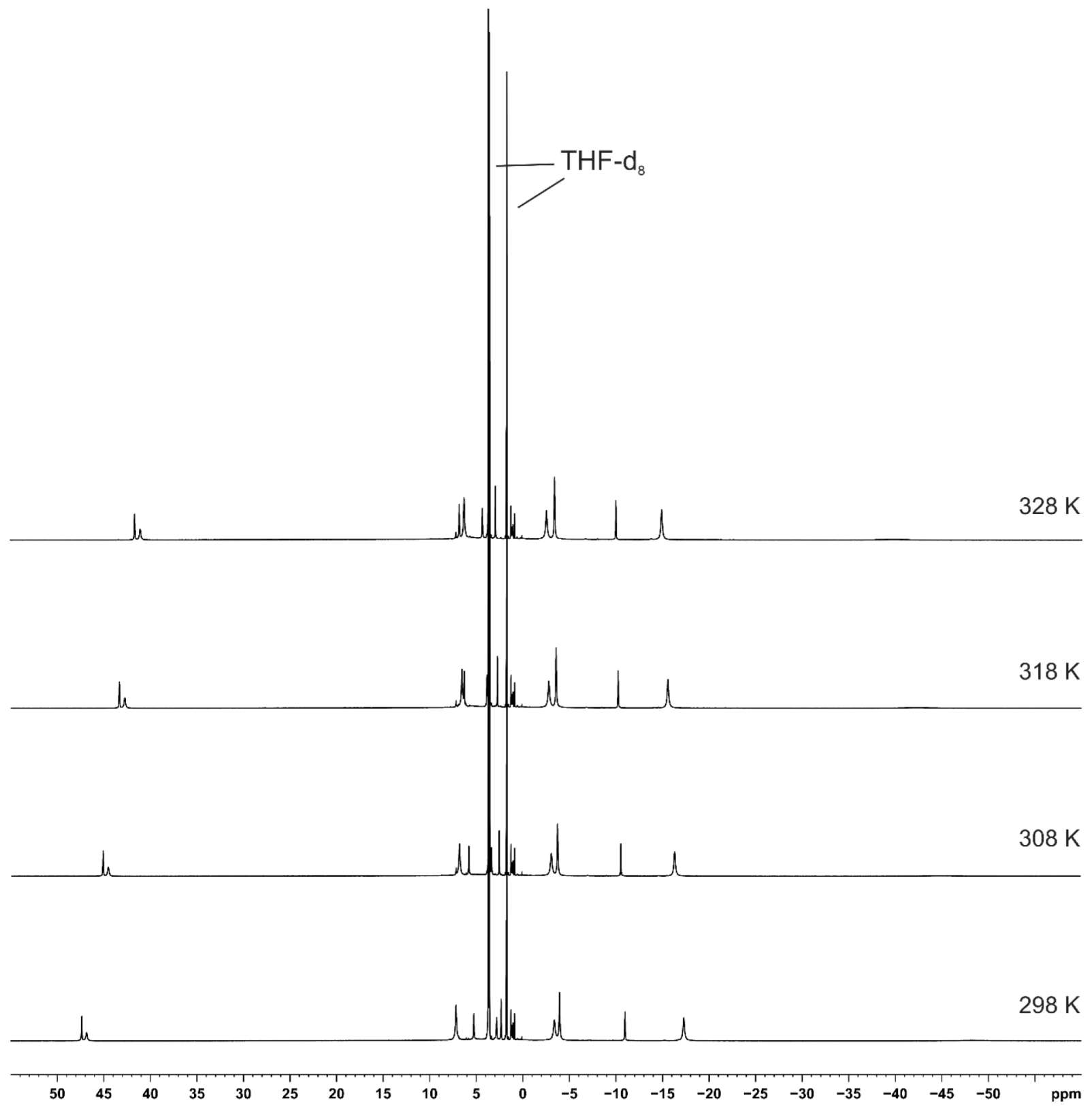

Figure 6. VT- ${ }^{1} \mathrm{H}$ NMR spectra $\left(400 \mathrm{MHz}\right.$, THF- $\left.d_{8}\right)$ of complex $3-[\mathrm{K}([18] \mathrm{c}-6)($ thf $)]\left(\right.$ sample $32^{-}-[\mathrm{K}([18] \mathrm{c}-6)($ thf $\left.)]\right)$ in the range from 298 to 328 K.

ligands is $42.2^{\circ}$ and the coordination geometry can therefore be described as neither square planar nor tetrahedral, but rather as a distorted structure that lies somewhere between these two extremes. The $\mathrm{C}-\mathrm{C}$ bond lengths of the $\alpha$-diimine

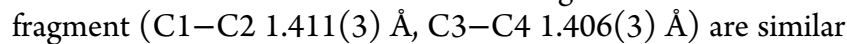
to those observed in $\mathrm{Na}_{2}$ [ ${ }^{\text {Dipp BIAN] }}(\mathrm{C} 1-\mathrm{C} 21.402(4) \AA)$, suggesting a dianionic BIAN ligand. It has to be mentioned though that the experimentally observed $\mathrm{C}-\mathrm{N}$ bond lengths $(\mathrm{C} 1-\mathrm{N} 11.351(3) \AA, \mathrm{C} 2-\mathrm{N} 21.359(2) \AA, \mathrm{C} 3-\mathrm{N} 31.362(3)$ $\AA$, C4-N4 1.364(2) $\AA$ ) are in between the values for the dianionic BIAN ligand in $\mathrm{Na}_{2}\left[{ }^{\text {Dipp }} \mathrm{BIAN}\right](\mathrm{C} 1-\mathrm{N} 11.387(4) \AA$, $\mathrm{C} 2-\mathrm{N} 2$ 1.386(4) $\AA$ ), and the monoanionic BIAN ligand (C1$\mathrm{N} 11.336(3) \AA, \mathrm{C} 1-\mathrm{N} 11.325(3) \AA)$ in $\left[\left({ }^{\mathrm{Dipp}} \mathrm{BIAN}\right) \mathrm{Ni}\left(\eta^{4}\right.\right.$ cod) $].{ }^{15,32}$ Consequently, a clear assignment from metric data is not feasible.

${ }^{1} \mathrm{H}$ NMR and EPR Spectroscopy. 1-[K([18]c-6) $\left.(\text { thf })_{0.5}\right]$ and 2 - $\left[\mathrm{K}([18] \mathrm{c}-6)(\mathrm{thf})_{2}\right]$ are paramagnetic according to ${ }^{1} \mathrm{H}$
NMR spectroscopy. 1-[K([18]c-6)(thf $\left.)_{0.5}\right]$ showed broad resonances from 9 to $-16 \mathrm{ppm}$ in THF- $d_{8}$, whereas 2$\left[\mathrm{K}([18] \mathrm{c}-6)(\mathrm{thf})_{2}\right]$ exhibits sharper signals in a range of 70 to -55 ppm (see Figures S1 and S2). Both complexes were also investigated by EPR spectroscopy in a 2-methyltetrahydrofuran ( $\left.{ }^{\mathrm{Me}} \mathrm{THF}\right)$ glass at $20 \mathrm{~K}$ (Figure 5). 1-[K([18]c-6)(thf $\left.)_{0.5}\right]$ shows a rhombic signal with $g_{11}=2.22, g_{22}=2.10$, and $g_{33}=$ 2.01. No hyperfine interaction (HFI) to nitrogen is observed, which in combination with the simulated $g$-values is consistent with the proposed $\mathrm{Fe}(\mathrm{I})$ structure from single-crystal X-ray crystallography. Calculation of the EPR parameters at the $\mathrm{B}^{2} \mathrm{LYP}^{33} /$ def2-TZVP ${ }^{34}$ level of theory gave $g$ values of 2.13 , 2.08 , and 2.01, which are close to the experimentally observed $g$ values. Hyperfine coupling constants were predicted to be small for all protons $\left(A^{\mathrm{H}} \leq 1 \mathrm{MHz}\right)$ and nitrogen atoms $\left(A^{\mathrm{N}}{ }_{11}\right.$ $=-4.73, A^{\mathrm{N}}{ }_{22}=-5.69$, and $\left.A^{\mathrm{N}}{ }_{33}=-7.61\right)$. In all cases, these coupling constants were too small to be observed in the 
obtained experimental spectrum. Moreover, the small $A^{\mathrm{N}}$ confirms the proposed spin density on the iron center and agrees with the presence of a dianionic closed-shell BIAN ligand. 2-[K([18]c-6)(thf $\left.)_{2}\right]$ shows a completely different EPR spectrum. Only a broad signal at half field was observed, which indicated the presence of an intermediate or high-spin iron complex. The experimental spectrum of 2 - $\left[\mathrm{K}([18] \mathrm{c}-6)(\mathrm{thf})_{2}\right]$ as approximated by simulation using the same approach as for complex 1-[K([18]c-6)(thf $\left.)_{0.5}\right]$ with an $S=3 / 2$ system and $g_{11}$ $=2.25, g_{22}=2.25, g_{33}=1.90, D=15 \mathrm{~cm}^{-1}, E=0.8 \mathrm{~cm}^{-1}(E / D$ $=0.05)$. Herein, $D$ and $E$ describe the axial and rhombic component of the zero field splitting, respectively. Notably, we were not able to satisfactorily simulate the experimental spectrum by consideration of an $S=5 / 2$ system.

Complex $3-[\mathrm{K}([18] \mathrm{c}-6)(\mathrm{thf})]$ is also paramagnetic in solution according to ${ }^{1} \mathrm{H}$ NMR spectroscopy in THF- $d_{8}$ and shows 14 resonances between +50 and $-50 \mathrm{ppm}$ (see Figure S3). This is almost in accordance with the expected number of resonances (15) for two chemically nonequivalent ${ }^{\text {Dipp }}$ BIAN ligands and one 18-crown-6 molecule. Another possibility is the presence of two isomeric complexes. Variable-temperature (VT) ${ }^{1} \mathrm{H}$ NMR spectra of sample $3_{2}-[\mathrm{K}([18] \mathrm{c}-6)(\mathrm{thf})]$ in the range from 298 to $328 \mathrm{~K}$ showed that no resonances appear or disappear upon heating and only minor shifts of the signals are observed (Figure 6).

The complex $3-[\mathrm{K}([18] \mathrm{c}-6)(\mathrm{thf})]$ (sample $3_{2}$ - $[\mathrm{K}([18] \mathrm{c}-$ 6)(thf)]) was analyzed by EPR spectroscopy in a ${ }^{\mathrm{Me}} \mathrm{THF}$ glass at $20 \mathrm{~K}$. The resulting spectrum of sample $3_{2}-[\mathrm{K}([18] \mathrm{c}-$ $6)($ thf $)]$ shows a rhombic signal with simulated $g$-values $\left(g_{11}=\right.$ 2.13, $\left.g_{22}=2.10, g_{33}=2.06\right)$ consistent with an $S=3 / 2$ ground state with large zero-field splitting and rhombicity $(D=20$ $\mathrm{cm}^{-1}, E=4.1 \mathrm{~cm}^{-1}, E / D=0.20$ ) (see Figure 7). Notably, no hyperfine interaction to nitrogen nuclei is observed.

${ }^{57} \mathrm{Fe}$ Mössbauer Spectroscopy. 1-[K([18]c-6)(thf $\left.)_{0.5}\right]$ and 2 - $\left[\mathrm{K}([18] \mathrm{c}-6)(\text { thf })_{2}\right]$ were further investigated by ${ }^{57} \mathrm{Fe}$

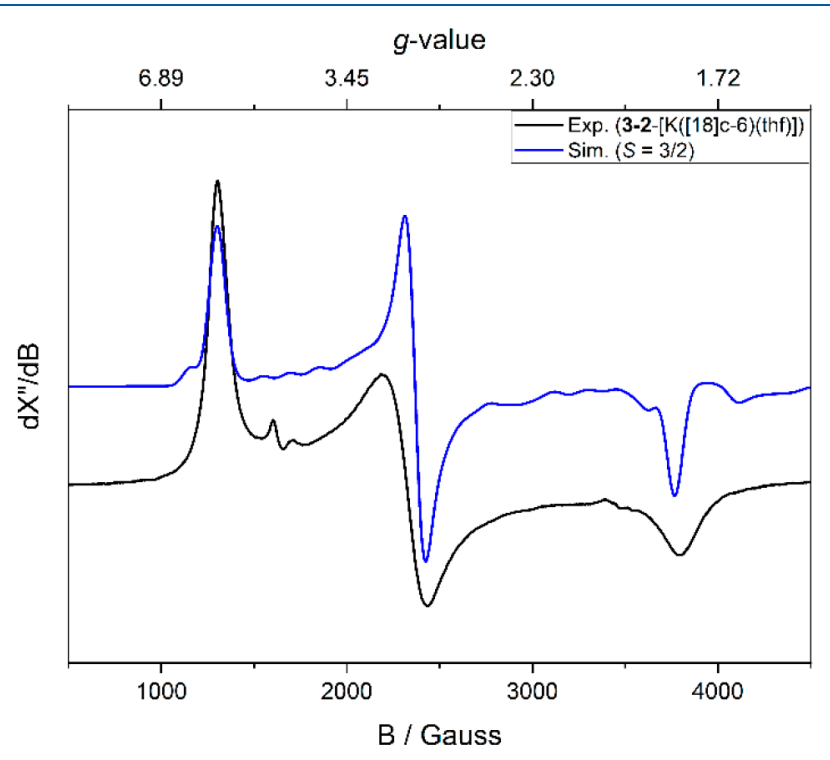

Figure 7. Experimental (Exp.) and simulated (Sim.) X-band EPR spectra of $3-[\mathrm{K}([18] \mathrm{c}-6)($ thf $)]$ (sample $3_{2}-[\mathrm{K}([18] \mathrm{c}-6)($ thf $)]$ ) recorded in ${ }^{\mathrm{Me}} \mathrm{THF}$ glass at $20 \mathrm{~K}$. Experimental parameters: microwave frequency, $9.375682 \mathrm{GHz}$; modulation amplitude, 4.000 G; power, $0.6325 \mathrm{~mW}$. Sample $3_{2}-[\mathrm{K}([18] \mathrm{c}-6)(\mathrm{thf})]$ can be simulated as an $S=3 / 2$ species: $g_{11}=2.13, g_{22}=2.10, g_{33}=2.06, D=20 \mathrm{~cm}^{-1}, E$ $=4.1 \mathrm{~cm}^{-1}, E / D=0.20$.
Mössbauer spectroscopy at $80 \mathrm{~K}$. A polycrystalline sample of $\mathbf{1}$ $\left[\mathrm{K}([18] \mathrm{c}-6)(\mathrm{thf})_{0.5}\right]$ showed an asymmetric doublet spectrum with an isomer shift of $\delta=0.23 \mathrm{~mm} \mathrm{~s}^{-1}$ and a quadrupole splitting of $\left|\Delta E_{\mathrm{Q}}\right|=2.26 \mathrm{~mm} \mathrm{~s}^{-1}$ (Figure 8, left). The asymmetry of the doublet spectrum is typical for an iron species with an odd number of unpaired electrons featuring slow paramagnetic relaxation, and it is consequently in line with the result of EPR spectroscopy. 2 - $\left[\mathrm{K}([18] \mathrm{c}-6)(\mathrm{thf})_{2}\right]$ also gave a doublet with a similar isomer shift of $\delta=0.17 \mathrm{~mm} \mathrm{~s}^{-1}$, but significantly smaller quadrupole splitting of $\left|\Delta E_{\mathrm{Q}}\right|=1.32$ $\mathrm{mm} \mathrm{s}^{-1}$ (Figure 8, right). The five coordinated pyridinediimine iron tetrazene complex $\left[\left({ }^{\mathrm{iPr}} \mathrm{PDI}\right) \mathrm{Fe}\{(\mathrm{NR}) \mathrm{NN}(\mathrm{NR})\}\right]$ $\left({ }^{\mathrm{iPr}} \mathrm{PDI}=2,6-(\mathrm{ArN}=\mathrm{CMe})_{2} \mathrm{C}_{5} \mathrm{H}_{3} \mathrm{~N} ; \mathrm{Ar}=\mathrm{Dipp}, \mathrm{R}=3,5-\right.$ $\mathrm{Me}_{2} \mathrm{C}_{6} \mathrm{H}_{3}$ ) prepared by Chirik and co-workers was proposed to have an intermediate-spin $\mathrm{Fe}$ (III) center based on Mössbauer parameters $\delta=0.43 \mathrm{~mm} \mathrm{~s}^{-1}$ and $\left|\Delta E_{\mathrm{Q}}\right|=1.37 \mathrm{~mm} \mathrm{~s}^{-1} ;^{35}$ whereas the isomer shift in $2-\left[\mathrm{K}([18] \mathrm{c}-6)(\text { thf })_{2}\right]$ is significantly lower, SQUID magnetometry (see below) indicates 2$\left[\mathrm{K}([18] \mathrm{c}-6)(\mathrm{thf})_{2}\right]$ to also feature intermediate-spin $\mathrm{Fe}(\mathrm{III})$,

Complex 3-[K([18]c-6)(thf)] was also investigated by ${ }^{57} \mathrm{Fe}$ Mössbauer spectroscopy at $80 \mathrm{~K}$. As shown in Figure 9, this polycrystalline sample of $3_{2}$ - $[\mathrm{K}([18] \mathrm{c}-6)(\mathrm{thf})]$ gave rise to a symmetric quadrupole doublet with an apparent isomer shift $\delta$ $=0.78 \mathrm{~mm} \mathrm{~s}^{-1}$ and $\left|\Delta E_{\mathrm{Q}}\right|=2.10 \mathrm{~mm} \mathrm{~s}^{-1}$. The values observed for $3_{2}-[K([18] \mathrm{c}-6)($ thf $)]$ are consistent with those of related high-spin $\mathrm{Fe}(\mathrm{II})$ complexes. For example, Holland and coworkers reported ${ }^{57} \mathrm{Fe}$ Mössbauer data for a neutral tetracoordinated iron complex with a tetrazene and a $\beta$ diketiminato ligand. ${ }^{36}$ This compound shows a similar ${ }^{57} \mathrm{Fe}$ Mössbauer isomer shift $\left(\delta=0.69(2) \mathrm{mm} \mathrm{s}^{-1}\right)$ and a smaller quadrupole splitting $\left(\left|\Delta E_{\mathrm{Q}}\right|=1.32(4) \mathrm{mm} \mathrm{s}^{-1}\right)$ as observed for $3_{2}-[\mathrm{K}([18] \mathrm{c}-6)($ thf $)]$. Comparable ${ }^{57} \mathrm{Fe}$ Mössbauer data have also been reported for the anionic reduction product of Holland's complex $\left(\delta=0.81(2) \mathrm{mm} \mathrm{s}^{-1},\left|\Delta E_{\mathrm{Q}}\right|=1.40(2) \mathrm{mm}\right.$ $\left.\mathrm{s}^{-1}\right) .{ }^{36}$ Nonetheless, the observed ${ }^{57} \mathrm{Fe}$ Mössbauer data are clearly in line with the presence of a high-spin Fe(II) species.

Magnetic Measurements. The ${ }^{57} \mathrm{Fe}$ Mössbauer data for complex 1- $\left[\mathrm{K}([18] \mathrm{c}-6)(\mathrm{thf})_{0.5}\right]$ are also in agreement with the magnetic moment $\mu_{\text {eff }}=2.0(1) \mu_{\mathrm{B}}$ determined in solution (THF- $d_{8}$ ) at ambient temperature by the Evans NMR method, ${ }^{37}$ which corresponds to one unpaired electron (spin-only value: $1.73 \mu_{\mathrm{B}}$ ). Unfortunately, SQUID magnetization measurements on $1-\left[\mathrm{K}([18] \mathrm{c}-6)(\text { thf })_{0.5}\right]$ were unsuccessful presumably due to the presence of minor amounts of ferromagnetic particles in the sample. 2 - $\left[\mathrm{K}([18] \mathrm{c}-6)(\mathrm{thf})_{2}\right]$ is also paramagnetic. The magnetic moment determined in solution (THF- $d_{8}$ ) by Evans NMR method is $\mu_{\text {eff }}=3.9(1) \mu_{\mathrm{B}}$ at ambient temperature, which is almost identical to the spinonly value for three unpaired electrons $\left(3.87 \mu_{\mathrm{B}}\right)$. A SQUID magnetization measurement in the temperature range 2-295 $\mathrm{K}$ gave $\chi_{\mathrm{M}} T=2.03 \mathrm{~cm}^{3} \mathrm{~mol}^{-1} \mathrm{~K}$ at $295 \mathrm{~K}$, which corresponds to $\mu_{\text {eff }}=4.0 \mu_{\mathrm{B}}$ (Figure 10). The measurement can be well simulated with a spin $S=3 / 2\left(g=2.08, D=17.0 \mathrm{~cm}^{-1}\right)$, which is in line with the EPR results. Thus, these experiments further support the assignment of an $\mathrm{Fe}$ (III) center with an intermediate spin of $S=3 / 2$.

The magnetic moment was determined for sample $\mathbf{3}_{2}$ $[\mathrm{K}([18] \mathrm{c}-6)($ thf $)]$ by the Evans NMR method in THF- $d_{8}$ solution. ${ }^{37}$ The observed magnetic moment was $\mu_{\text {eff }}=4.7(1)$ $\mu_{\mathrm{B}}\left(\right.$ or $\left.\chi_{\mathrm{M}} \mathrm{T}=2.76 \mathrm{~cm}^{3} \mathrm{~mol}^{-1} \mathrm{~K}\right)$ at ambient temperature. This value is much closer to the calculated spin-only values for three unpaired electrons $\left(1.875 \mathrm{~cm}^{3} \mathrm{~mol}^{-1} \mathrm{~K}\right.$; quartet state) than for five unpaired electrons $\left(4.375 \mathrm{~cm}^{3} \mathrm{~mol}^{-1} \mathrm{~K}\right.$; sextet state $)$. 

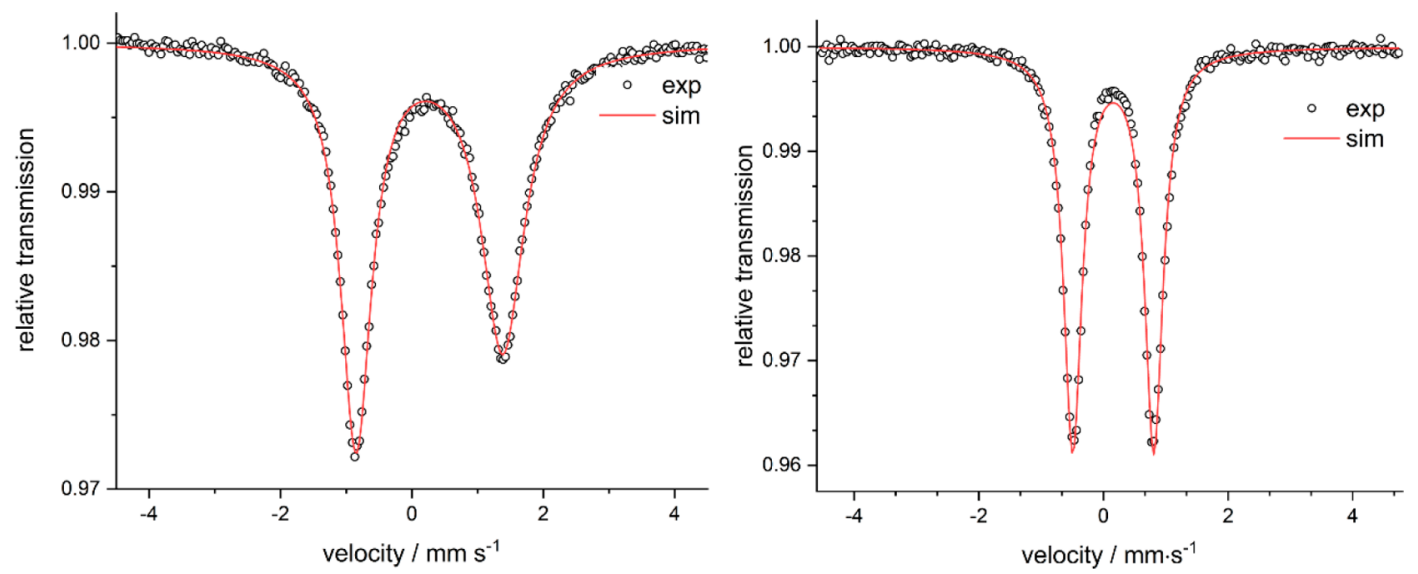

Figure 8. ${ }^{57} \mathrm{Fe}$ Mössbauer spectra of 1-[K([18]c-6)(thf $\left.)_{0.5}\right]$ (left) and 2-[K([18]c-6)(thf) $\left.)_{2}\right]$ (right); exp = experimental, sim = simulated.

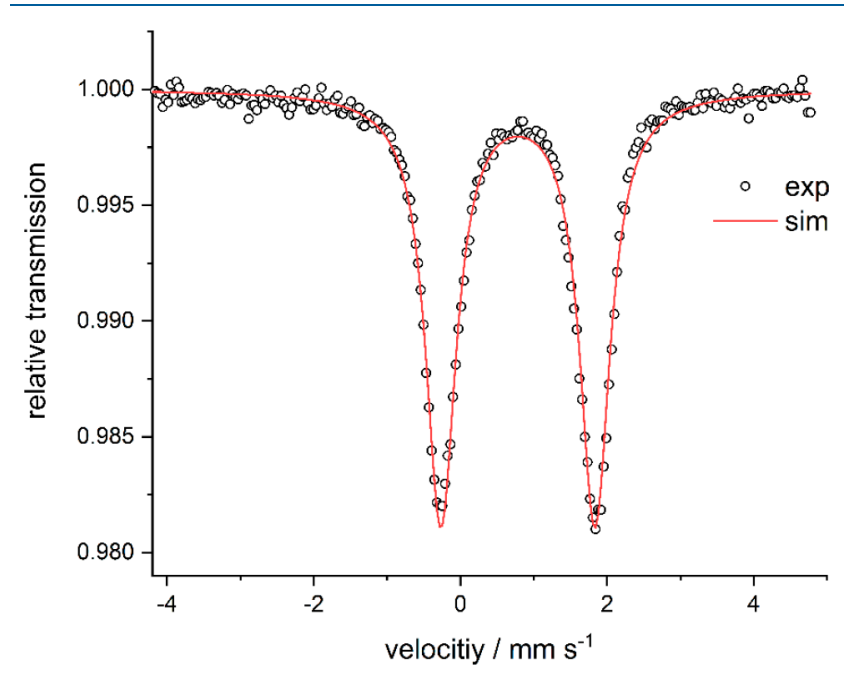

Figure 9. ${ }^{57} \mathrm{Fe}$ Mössbauer spectrum of sample $3_{2}-[\mathrm{K}([18] \mathrm{c}-6)(\mathrm{thf})]$; $\exp =$ experimental, $\operatorname{sim}=$ simulated.

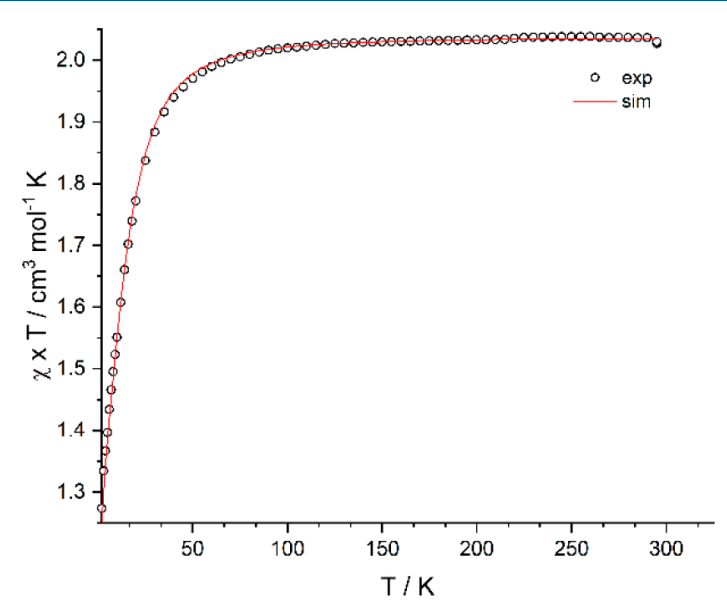

Figure 10. $\chi_{\mathrm{M}} T$ versus $T$ plot of $2-\left[\mathrm{K}([18] \mathrm{c}-6)(\mathrm{thf})_{2}\right] ; \exp =$ experimental, sim $=$ simulated.

For more detailed analysis, the SQUID experiments on solid $3_{2}-[\mathrm{K}([18] \mathrm{c}-6)(\mathrm{thf})]$ in form of variable temperature-variable field (VTVH) magnetization measurement as well as temperature dependent susceptibility measurement were performed (Figure 11). The VTVH measurement can be successfully fitted assuming an $S=3 / 2$ model as a result of strong antiferromagnetic coupling of a HS-Fe(II) ion $(S=2)$ with the ligand based radical $(S=1 / 2)$ with fit parameters $g=2.38$ and $D=22.5 \mathrm{~cm}^{-1}$. The simulation of the $\chi_{\mathrm{M}} T$ measurement with these parameters reveals a deviation from this model at temperatures higher than $50 \mathrm{~K}$. This deviation may be explained by the presence of a small amount of magnetic nanoparticles, which are even not detectable by elemental analysis and ${ }^{57} \mathrm{Fe}$ Mössbauer, but are known to be readily formed under highly reducing conditions as used for the synthesis of the present iron complexes. The magnetization of these particles is saturated and consequently their magnetic susceptibility vanishes at high magnetic fields in VTVH measurements. Attempts to analyze the $\chi_{\mathrm{M}} T$ curve using a model with two spin carriers and moderate antiferromagnetic exchange were unsuccessful.

Quantum-Chemical Calculations. Theoretical investigations using DFT and CASSCF methods were used to analyze the electronic structures of the anions of $1-[\mathrm{K}([18] \mathrm{c}$ $\left.6)(\text { thf })_{0.5}\right]$ and 2 - $\left[\mathrm{K}([18] \mathrm{c}-6)(\text { thf })_{2}\right]$ in comparison with experimental results. Geometries were optimized at the OPBE-D3BJ/def2-TVZP ${ }^{34,38,39}$ level of theory in the gas phase. The optimized geometry for the anion of $1-[\mathrm{K}([18] \mathrm{c}$ 6) (thf $\left.)_{0.5}\right]$ is in good agreement with the structure determined by single-crystal X-ray crystallography. DFT calculations confirmed that spin density is localized at the metal center, as shown in Figure 12 (left). Analysis of the orbitals showed that the highest occupied orbital is a singly occupied molecular orbital (SOMO) with high d character (see the Supporting Information). Thus, a $\mathrm{d}^{7}$ electronic configuration with a $\mathrm{Fe}(\mathrm{I})$ species is plausible and consistent with experimental and theoretical data. State-averaged CASSCF-DLPNO-NEVPT2/ def2-mTZVP def2-TZVP/C calculations were conducted including three different ground state multiplicities $\left(M_{\mathrm{s}}=2 S\right.$ $+1=2,4,6)$ to get an insight into the electronic structure of the anion of $2-\left[\mathrm{K}([18] \mathrm{c}-6)(\mathrm{thf})_{2}\right]$. The quartet state was energetically most favored while the sextet $(\Delta E=+39.9 \mathrm{kcal}$ $\left.\mathrm{mol}^{-1}\right)$ and doublet state $\left(\Delta E=+26.6 \mathrm{kcal} \mathrm{mol}{ }^{-1}\right)$ are significantly higher in energy. The quartet state corresponds to an $\mathrm{Fe}(\mathrm{III})$ intermediate spin system $(S=3 / 2)$ with $\mathrm{d}^{5}$ configuration at iron. Moreover, the spin-density obtained from a single-point DFT calculation is mainly localized on the metal center (Figure 12, right). Thus, the theoretical data are consistent with the experimental data.

The anion of $3-[\mathrm{K}([18] \mathrm{c}-6)(\mathrm{thf})]$ was analyzed using the same computational method (CASSCF) as mentioned for 

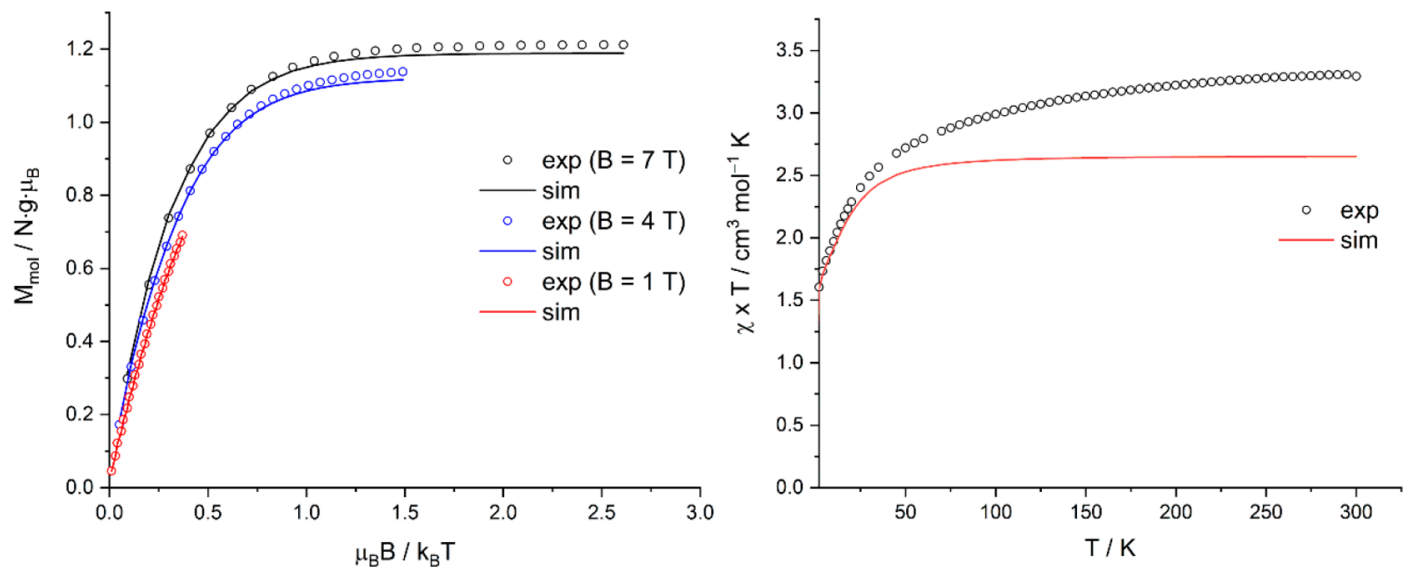

Figure 11. Variable temperature-variable field (VTVH) magnetization measurements as $M_{\text {mol }}$ versus $\mu_{\mathrm{B}} B / k_{\mathrm{B}} T$ (left) and $\chi_{\mathrm{M}} T$ versus $T$ plot at 0.5

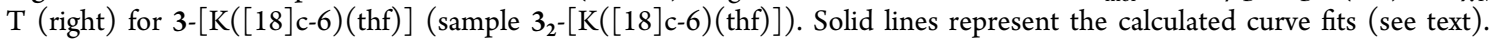
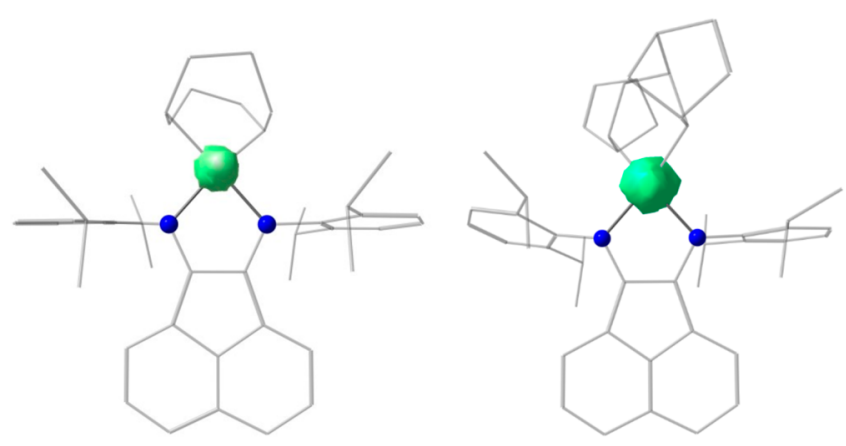

Figure 12. Spin-density plots according to Mulliken population analysis of $1-\left[\mathrm{K}([18] \mathrm{c}-6)(\text { thf })_{0.5}\right]$ (left) and 2 -[K([18]c-6)(thf) $\left.{ }_{2}\right]$ (right); isosurface value $=0.05$.

complex 2-[K([18]c-6)(thf $\left.)_{2}\right]$. For both complexes, the doublet states are significantly higher in energy $(+21 \mathrm{kcal}$ $\mathrm{mol}^{-1}$ ) compared to the most stable high-spin configuration. The quartet and sextet configurations are very similar in energy, the former being preferred by $1.7 \mathrm{kcal} \mathrm{mol}^{-1}$ for complex 3-[K([18]c-6)(thf)]. On the basis of an analysis of the orbital occupations resulting from the CASSCF-DLPNONEVPT2 calculations, a high-spin Fe(II) center with one monoanionic and one dianionic BIAN ligand is conceivable for complex 3- $[\mathrm{K}([18] \mathrm{c}-6)(\mathrm{thf})]$ (see the Supporting Information for a detailed discussion of the quantum chemical calculations).

Cyclic Voltammetry. Complexes 1-[K([18]c-6)(thf $\left.)_{0.5}\right]$ and $2-\left[\mathrm{K}([18] \mathrm{c}-6)(\text { thf })_{2}\right]$ both possess two potentially redoxactive sites: the central iron atom and the redox-active BIAN ligand. Both complexes are similar in their redox properties according to their cyclic voltammograms (Figures 13 and 14). One reversible and at least one irreversible oxidation is observed. In the case of complex 1 , the chemically reversible process at $E_{1 / 2}=-1.98 \mathrm{~V} \mathrm{vs} \mathrm{Fc} / \mathrm{Fc}^{+}$is consistent with previous results by Findlater and co-workers, who prepared the neutral complex $\left[\left({ }^{\mathrm{Dipp}} \mathrm{BIAN}\right) \mathrm{Fe}\left(\eta^{4}\right.\right.$-cod $\left.)\right]$ by $\mathrm{Na} / \mathrm{Hg}$ reduction of $\left[\left({ }^{\text {Dipp }} \mathrm{BIAN}\right) \mathrm{FeCl}_{2}\right]$ and $\operatorname{cod}^{18}$ On the basis of the structural data obtained for the anionic complex 1-[K([18]c-6)(thf $\left.)_{0.5}\right]$ (vide supra) and the neutral compound [( $\left.{ }^{\text {Dipp }} \mathrm{BIAN}\right) \mathrm{Fe}\left(\eta^{4}\right.$ cod)] reported by Findlater and co-workers, both species presumably contain an $\mathrm{Fe}(\mathrm{I})$ center. The structural parameters (in particular $\mathrm{C}-\mathrm{C}$ and $\mathrm{C}-\mathrm{N}$ bond lengths) suggest the presence of a $\mathrm{BIAN}^{2-}$ dianion in $1-\left[\mathrm{K}([18] \mathrm{c}-6)(\mathrm{thf})_{0.5}\right]$ and a $\mathrm{BIAN}^{-}$monoanion in $\left[\left({ }^{\mathrm{Dipp}} \mathrm{BIAN}\right) \mathrm{Fe}\left(\eta^{4}-\mathrm{cod}\right)\right]$. Accordingly, the reversible process observed for $1-\left[\mathrm{K}([18] \mathrm{c}-6)(\mathrm{thf})_{0.5}\right]$ at $E_{1 / 2}=-1.98 \mathrm{~V}$ vs $\mathrm{Fc} / \mathrm{Fc}^{+}$may be assigned as a ligand-centered redox event.

Complex 2-[K([18]c-6)(thf $\left.)_{2}\right]$ can also be reversibly oxidized by one electron at a similar, but slightly less negative potential $\left(E_{1 / 2}=-1.71 \mathrm{~V}\right.$ vs $\left.\mathrm{Fc} / \mathrm{Fc}^{+}\right)$. Based on the similar
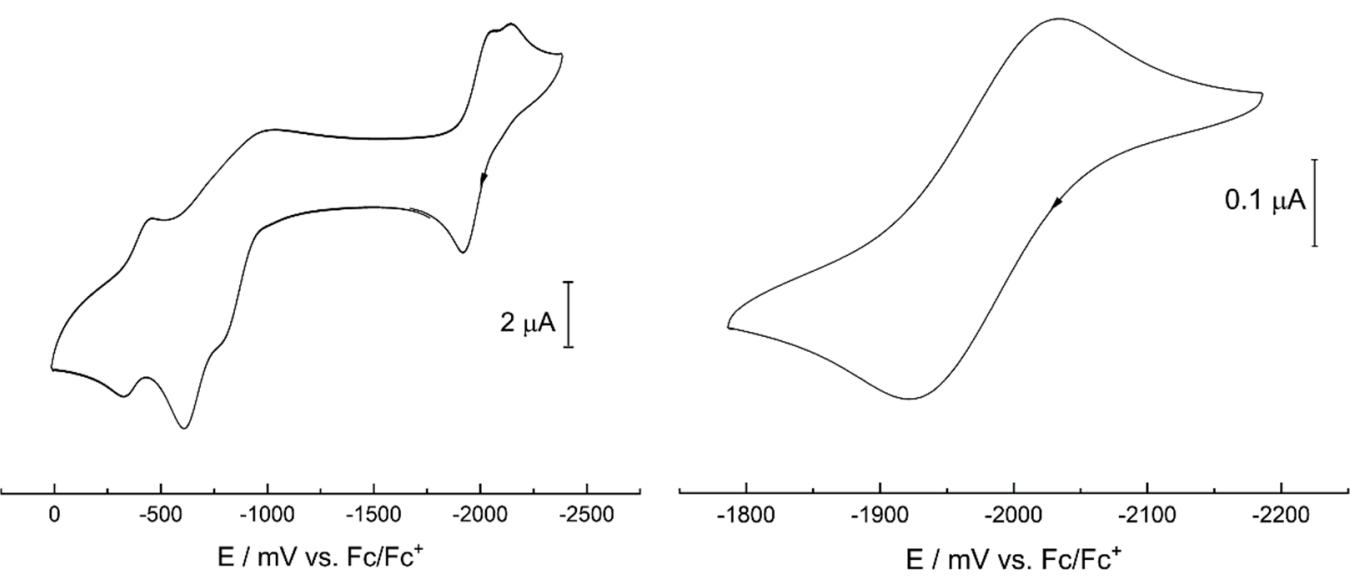

Figure 13. Cyclic voltammograms of $1-\left[\mathrm{K}([18] \mathrm{c}-6)(\mathrm{thf})_{0.5}\right]$ in $\mathrm{THF} /{ }^{n} \mathrm{Bu}_{4} \mathrm{NPF}_{6}$, scan rate: $100 \mathrm{mV} \mathrm{s} \mathrm{s}^{-1}$ (left) and $50 \mathrm{mV} \mathrm{s}{ }^{-1}$ (right). 

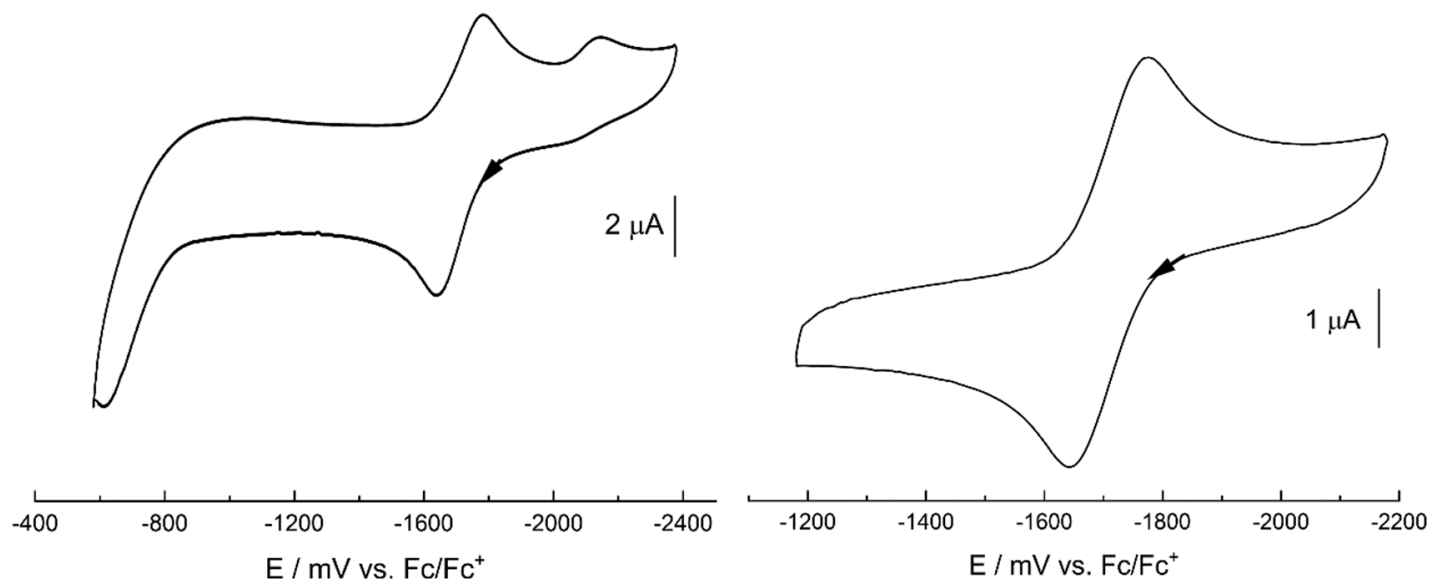

Figure 14. Cyclic voltammograms of 2 - $\left[\mathrm{K}([18] \mathrm{c}-6)(\text { thf })_{2}\right]$ in $\mathrm{THF} /{ }^{n} \mathrm{Bu}_{4} \mathrm{NPF}_{6}$, scan rate: $100 \mathrm{mV} \mathrm{s}^{-1}$ (left) and $50 \mathrm{mV} \mathrm{s}$ (right).
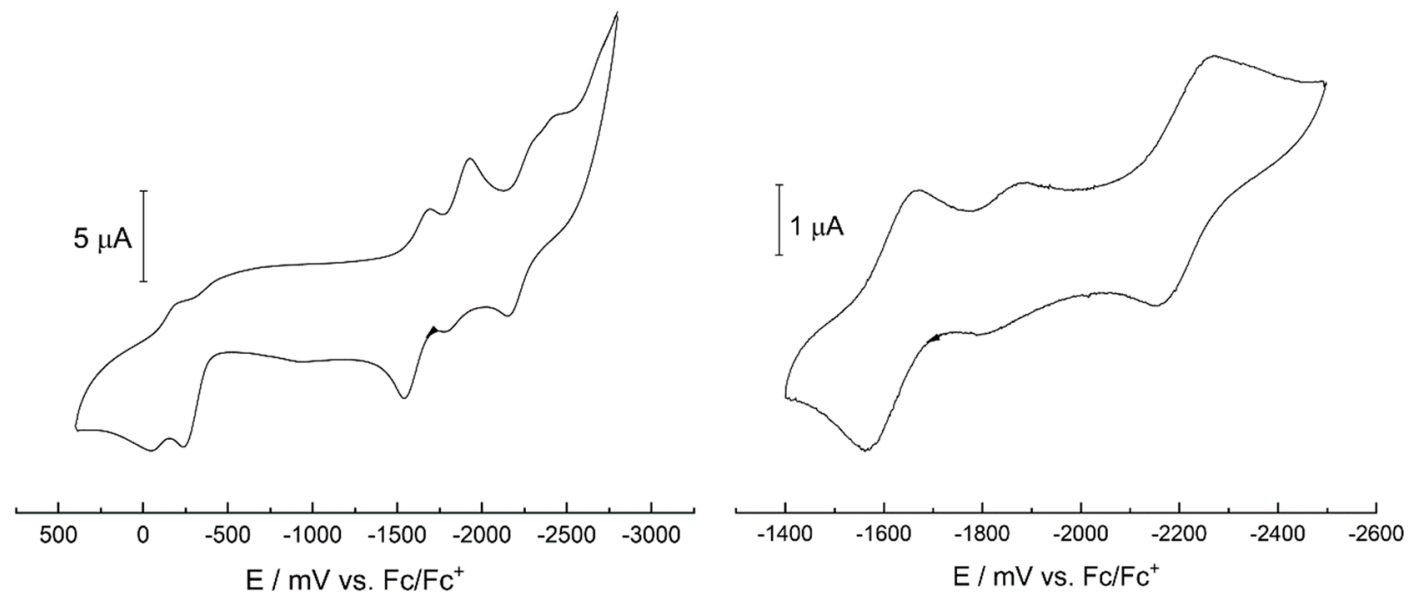

Figure 15. Cyclic voltammogram of $3_{2^{-}}[\mathrm{K}([18] \mathrm{c}-6)(\mathrm{thf})]$ in $\mathrm{THF} /{ }^{n} \mathrm{Bu}_{4} \mathrm{NPF}_{6}$ in the range -2750 to $500 \mathrm{mV}$ (left, scan rate: $\left.100 \mathrm{mV} \mathrm{s}{ }^{-1}\right)$ and -2500 to $-1400 \mathrm{mV}$ (right, $50 \mathrm{mV} \mathrm{s}^{-1}$ ).

structure of $\mathbf{1}-\left[\mathrm{K}([18] \mathrm{c}-6)(\mathrm{thf})_{0.5}\right]$ and $\mathbf{2}-\left[\mathrm{K}([18] \mathrm{c}-6)(\mathrm{thf})_{2}\right]$, we speculate that this also a ligand-centered process. An additional irreversible process observed at $-0.85 \mathrm{~V}$ for 1$\left[\mathrm{K}([18] \mathrm{c}-6)(\text { thf })_{0.5}\right]$ and $-0.8 \mathrm{~V}$ for $2-\left[\mathrm{K}([18] \mathrm{c}-6)(\text { thf })_{2}\right]$ is assigned to the oxidation of the complexes.

Complex 3-[K([18]c-6)(thf)] shows three potentially redoxactive sites (one iron atom and two $\alpha$-diimine ligands). The cyclic voltammograms $(\mathrm{CVs})$ of sample $3_{2}-[\mathrm{K}([18] \mathrm{c}-6)(\mathrm{thf})]$ were recorded in $\mathrm{THF} /{ }^{n} \mathrm{Bu}_{4} \mathrm{NPF}_{6}$. The CV of $3_{2}-[\mathrm{K}([18] \mathrm{c}-$ 6)(thf)] shows two quasi-reversible processes with waves at -1.6 and $-2.2 \mathrm{~V}$ vs $\mathrm{Fc} / \mathrm{Fc}^{+}$and waves assigned to quasireversible or irreversible processes at $-0.4 \mathrm{~V}$ and $-0.2 \mathrm{~V}$ (Figure 15). As mentioned in the Introduction, Fedushkin and co-workers synthesized the neutral $\left[\left({ }^{\text {(ipp }} \mathrm{BIAN}\right)_{2} \mathrm{Fe}\right]$ complex and proposed an $\mathrm{Fe}(\mathrm{II})$ center with two monoanionic BIAN ligands. ${ }^{24}$ On the basis of this assignment, it seems likely that the first oxidation event is a ligand-centered process. There is an additional wave at $-1.8 \mathrm{~V}$, which might arise from a secondary redox process or an impurity. Moreover, the CV of sample $3_{2}-[\mathrm{K}([18] \mathrm{c}-6)(\mathrm{thf})]$ shows an irreversible reduction at $-2.7 \mathrm{~V}$.

Catalytic Hydroboration of Carbonyl Compounds. Because of their high reduction potential, it was anticipated that complexes 1-3 should be excellent candidates as catalysts for reductive transformations such as hydrogenation, hydroboration, and hydrosilylation. As already mentioned in the
Introduction, it is a key challenge to develop earth-abundant transition metal catalysts. ${ }^{40}$ The catalytic hydroboration of carbonyl compounds using pinacolborane (HBpin) was chosen as a proof of principle, which is an important organic reaction and affords widely used borate esters and the corresponding alcohols by facile hydrolysis. ${ }^{41,42}$ This catalytic reaction has been intensively studied using precious metal catalysts, but there has also been recent progress in using $3 \mathrm{~d}$ metal complexes based on $\mathrm{Mn},{ }^{43} \mathrm{Co},{ }^{44} \mathrm{Ni},{ }^{45}$ and Fe. ${ }^{46-51}$ Although there is a number of reports on iron-catalyzed alkene hydroboration, only a few examples for the hydroboration of carbonyl compounds are described in literature. Findlater and co-workers reported the hydroboration of ketones and aldehydes with HBpin (1.5 equiv.) using catalytic amounts of $\mathrm{Fe}(\mathrm{acac})_{3}(10 \mathrm{~mol} \%)$ and $\mathrm{NaBEt}_{3} \mathrm{H}(10 \mathrm{~mol} \%)$ in THF. The reaction proceeds to completion at ambient temperature within 1 day. ${ }^{46}$ Subsequently, Bai and co-workers described a more efficient system suitable for various ketones and aldehydes using a lower catalyst loading $(2.5 \mathrm{~mol} \%)$ based on a low-coordinate tritert-butylphosphoranimido-iron(II) dimer. ${ }^{47}$ An iron(II) hydride complex was also developed by Tong, Wang, and co-workers and used for the exclusive hydroboration of aldehydes at low catalyst loading $(0.1 \mathrm{~mol}$ $\%) .{ }^{48}$ One of the most active systems for aldehydes so far is an imine coupled $\left[\mathrm{Fe}-\mathrm{N}_{2} \mathrm{~S}_{2}\right]_{2}$ complex $(0.1 \mathrm{~mol} \%)$ reported by Baker and co-workers, which is capable of reducing aldehydes 
to primary borate esters with $\mathrm{HB}$ pin within $30 \mathrm{~min}$ at ambient temperature. ${ }^{49}$ Two systems based on the cooperation of iron and silicon were reported by Fenske and co-workers and So and co-workers. Both systems were applied in the hydroboration of ketones at ambient temperature with HBpin and catalyst loadings of $1 \mathrm{~mol} \%$ (Fenske) or $10 \mathrm{~mol} \%$ (So). ${ }^{50}$ Recently, Gade and co-workers showed that a chiral bis(oxazolinyl-methylidene)isoindoline iron alkyl complex is able to catalyze the hydroboration of various functionalized ketones, which led to chiral halohydrines, oxaheterocycles, and amino-alcohols after workup. These reactions were performed at $-30{ }^{\circ} \mathrm{C}$ and achieved remarkable turnover frequencies of more than $40000 \mathrm{~h}^{-1}$. 51

We decided to investigate the hydroboration of acetophenone using 1-3 and HBpin as a model reaction (Table 1).

Table 1. Hydroboration of Acetophenone with HBPin Using Fe Precatalysts 1-3

\begin{tabular}{|c|c|c|c|c|c|}
\hline entry & catalyst(mol \%) & $\begin{array}{l}\text { HBpin } \\
\text { (equiv.) }\end{array}$ & $\begin{array}{l}\text { solvent } \\
(\mathrm{mL})\end{array}$ & $\begin{array}{l}\text { time } \\
(\mathrm{min})\end{array}$ & $\begin{array}{c}\text { yield }^{a} \\
(\text { conversion })^{a}\end{array}$ \\
\hline 1 & $\begin{array}{c}1-[\mathrm{K}([18] \mathrm{c}-6) \\
\left.\quad(\text { thf })_{0.5}\right](0.1)\end{array}$ & 1.03 & $\begin{array}{l}\text { THF } \\
(0.1)\end{array}$ & 10 & $>99$ \\
\hline 2 & $\begin{array}{r}2-[\mathrm{K}([18] \mathrm{c}-6) \\
\left.\quad(\text { thf })_{2}\right](0.1)\end{array}$ & 1.03 & $\begin{array}{l}\mathrm{THF} \\
(0.1)\end{array}$ & 10 & $>99$ \\
\hline 3 & $\begin{array}{c}3-[\mathrm{K}([18] \mathrm{c}-6) \\
\text { (thf)] }(0.1)\end{array}$ & 1.03 & $\begin{array}{l}\text { THF } \\
(0.1)\end{array}$ & 10 & $67(67)$ \\
\hline
\end{tabular}

${ }^{a}$ Yields and conversions were determined by quantitative GC vs internal $n$-pentadecane.

Optimization of the reaction conditions was performed using $\alpha$-diimine ferrate 1 - $\left[\mathrm{K}([18] \mathrm{c}-6)(\text { thf })_{0.5}\right]$. Best activity and full conversion were first obtained using $0.1 \mathrm{~mol} \%$ catalyst loading and a small excess of HBpin (1.03 equiv.) at $25{ }^{\circ} \mathrm{C}$ in THF. Under these optimized conditions, the complexes $2-[\mathrm{K}([18] \mathrm{c}-$ $\left.6)(\text { thf })_{2}\right]$ and $3-[\mathrm{K}([18] \mathrm{c}-6)(\mathrm{thf})]$ were tested as well. Although the homoleptic complex $3-[\mathrm{K}([18] \mathrm{c}-6)(\mathrm{thf})]$ is significantly less active than $1-\left[\mathrm{K}([18] \mathrm{c}-6)(\text { thf })_{0.5}\right]$, the heteroleptic complex 2-[K([18]c-6)(thf $\left.)_{2}\right]$ displayed similar activity. A plausible reason for the different reactivities of 1$\left[\mathrm{K}([18] \mathrm{c}-6)(\mathrm{thf})_{0.5}\right] / 2-\left[\mathrm{K}([18] \mathrm{c}-6)(\mathrm{thf})_{2}\right]$ and 3-[K([18]c-6)(thf)] is the absence of a vacant coordination site. However, the activation processes for $1-\left[\mathrm{K}([18] \mathrm{c}-6)(\text { thf })_{0.5}\right]$ and 2$\left[\mathrm{K}([18] \mathrm{c}-6)(\mathrm{thf})_{2}\right]$ must be different because of the fact that 2$\left[\mathrm{K}([18] \mathrm{c}-6)(\mathrm{thf})_{2}\right]$ is coordinated by two alkyl ligands.

Complex 1-[K([18]c-6)(thf $\left.)_{0.5}\right]$ was selected for further investigations. The optimized reaction conditions described above using $0.1 \mathrm{~mol} \%$ of catalyst were applied to various parasubstituted acetophenone derivatives, in order to investigate functional group tolerance. Gratifyingly, the system was found to be compatible with electron-donating ( $\mathrm{OMe}, \mathrm{Me})$, as well as electron-withdrawing groups $\left(\mathrm{CF}_{3}\right)$. Furthermore, halogenated $(\mathrm{F}, \mathrm{Cl}, \mathrm{Br}, \mathrm{I}$ ) acetophenones were cleanly hydroborated with no observable dehydrohalogenation, a problem sometimes observed for other highly reduced metalates. ${ }^{25}$ Pendant amine $\left(\mathrm{NMe}_{2}\right)$ and carboxylic ester (COOMe) were also tolerated. Furthermore, efficient hydroboration was observed for 3methylacetophenone, propiophenone, the aliphatic substrate 2octanone, and 2-acetyl pyridine (Scheme 4). More sterically hindered substrates such as 2-methylacetophenone or benzophenone were also viable substrates, although slightly extended reaction times were required to achieve full conversion. Prolonged reaction times were also necessary for substrates such as 1-cylohexylethan-1-one, benzaldehyde, and $\alpha, \beta$-unsaturated ketones. The hydroboration of 4-nitroaceto-

Scheme 4. Substrate Scope for the Hydroboration of Carbonyls Catalyzed by $1-\left[\mathrm{K}([18] \mathrm{c}-6)(\mathrm{thf})_{0.5}\right]^{a}$

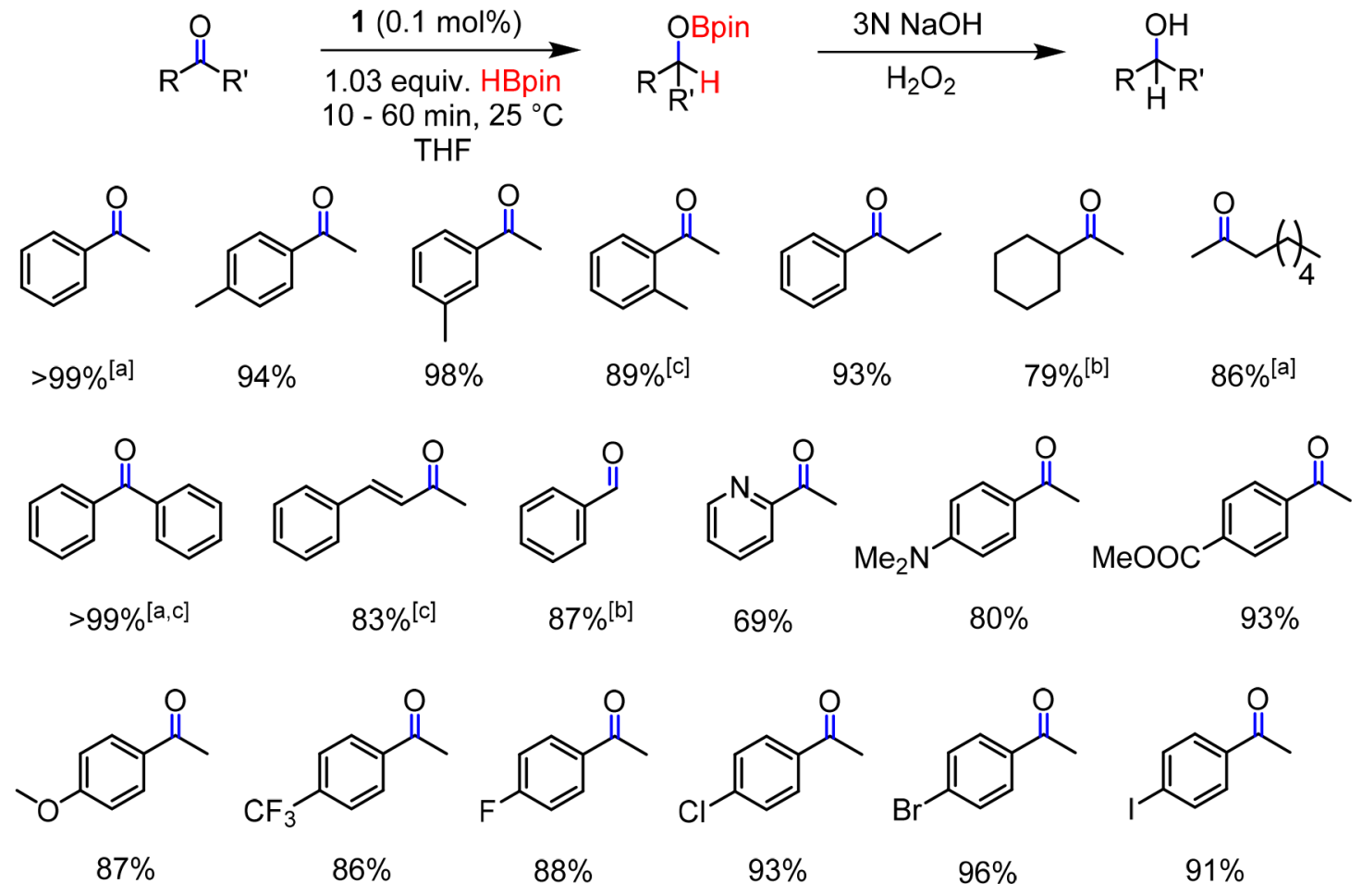

${ }^{a}$ Yields correspond to isolated alcohols. Reaction conditions: Substrate $(1 \mathrm{mmol}), \mathrm{HBpin}(1.03 \mathrm{mmol}), \mathbf{1}-\left[\mathrm{K}([18] \mathrm{c}-6)(\mathrm{thf})_{0.5}\right](0.001 \mathrm{mmol}), \mathrm{THF}$ $(0.5 \mathrm{~mL}), 25{ }^{\circ} \mathrm{C}$. [a] = yield determined by quantitative GC-FID vs. internal $n$-pentadecane; [b] $30 \mathrm{~min}$; [c] $1 \mathrm{~h}$. 

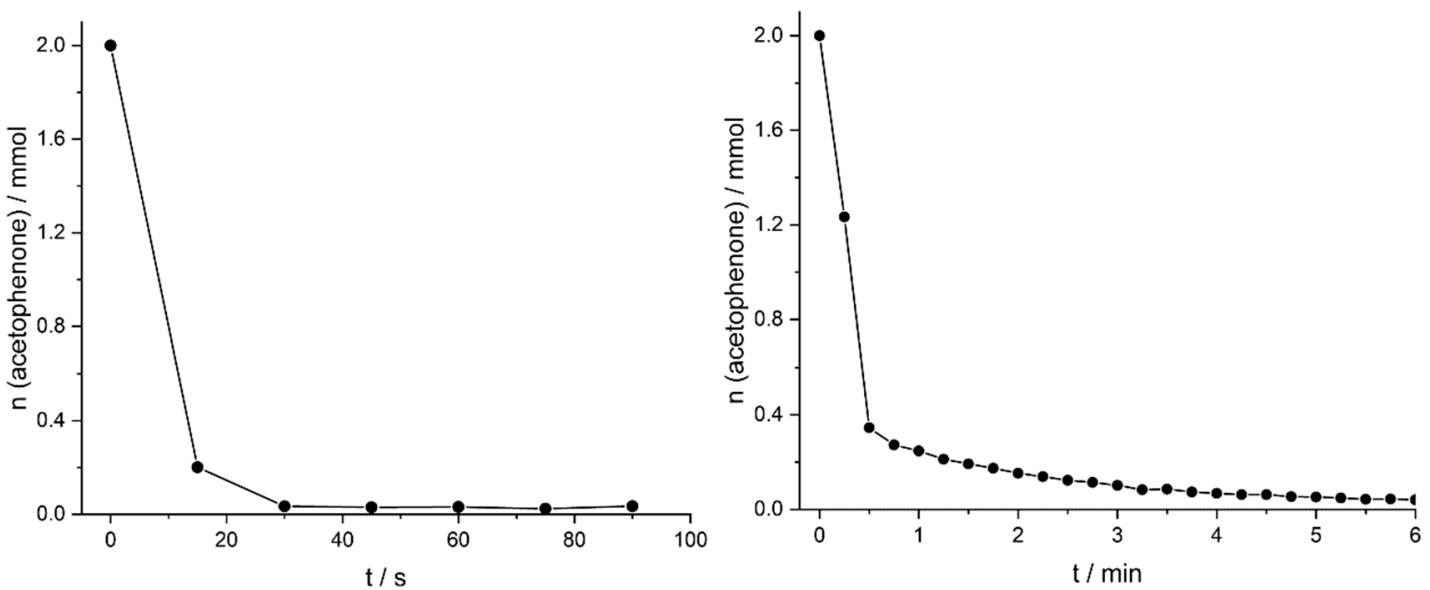

Figure 16. Reaction profile for of the hydroboration of acetophenone by HBpin catalyzed by 1-[K([18]c-6)(thf) $\left.)_{0.5}\right]$. Reaction conditions: Acetophenone $(2 \mathrm{mmol}), \mathrm{HBpin}(2 \mathrm{mmol}), 1-\left[\mathrm{K}([18] \mathrm{c}-6)(\mathrm{thf})_{0.5}\right]\left(0.05 \mathrm{~mol} \%\right.$ (left), $0.036 \mathrm{~mol} \%$ (right)), THF $(4 \mathrm{~mL}), 25^{\circ} \mathrm{C} . \mathrm{Data}$ points were obtained from time-resolved FT-IR spectra (see the Supporting Information for details).

phenone was not selective as nitro group reduction was observed as well. 4-Acetylphenol was not hydroborated at all. Notably, no $\mathrm{C}=\mathrm{C}$ bond reduction was observed for $\alpha, \beta$ unsaturated ketone substrates. Moreover, the aldehyde group in 4-acetylbenzaldehyde was hydroborated more rapidly than the ketone moiety as proven by GC-MS, despite benzaldehyde itself requiring a longer reaction time for conversion than acetophenone.

In order to gain more insight into the reaction mechanism, the model hydroboration reaction of acetophenone, the decrease in the $\mathrm{C}=\mathrm{O}$ stretching band $\left(\nu_{(\mathrm{C}=\mathrm{O})}=1689\right.$ $\mathrm{cm}^{-1}$ ) was monitored by in situ IR spectroscopy (Figure 16). Full consumption of acetophenone was achieved within $30 \mathrm{~s}$ at $25{ }^{\circ} \mathrm{C}$ with a catalyst loading of $0.05 \mathrm{~mol} \%$ (1-[K([18]c$\left.\left.6)(\text { thf })_{0.5}\right]\right)$; this corresponds to a turnover frequency of $220000 \mathrm{~h}^{-1}$. Catalyst $1-\left[\mathrm{K}([18] \mathrm{c}-6)(\mathrm{thf})_{0.5}\right]$ therefore represents one of the most active iron catalysts for the hydroboration of ketones reported to date. For comparison, a turnover frequency of $43500 \mathrm{~h}^{-1}$ at $-30{ }^{\circ} \mathrm{C}$ was reported by Gade and co-workers for $4^{\prime}$-fluoroacetophenone hydroboration of HBPin using the current state-of-the-art bis(oxazolinylmethylidene)isoindoline iron catalyst. ${ }^{51}$

In addition to this monitoring study, we also conducted a poisoning experiment using mercury, which is known to selectively inhibit the catalytic activity of heterogeneous catalysts. The hydroboration of acetophenone by 1 - $[\mathrm{K}([18]$ $\left.\mathrm{c}-6)(\text { thf })_{0.5}\right]$ was not negatively influenced by the presence of mercury (one drop). ${ }^{52}$ Several illustrative stoichiometric reactions were also carried out. The reaction of a molar 1:1 ratio of $1-\left[\mathrm{K}([18] \mathrm{c}-6)(\text { thf })_{0.5}\right]$ and HBPin did not lead to any new signal in the ${ }^{11} \mathrm{~B}$ NMR spectrum, suggesting a lack of any direct, productive reaction between these two components. Conversely, a brown solution of $1-\left[\mathrm{K}([18] \mathrm{c}-6)(\text { thf })_{0.5}\right]$ turned immediately green upon addition of 1 equiv. of acetophenone. Moreover, the $\nu_{(\mathrm{C}=\mathrm{O})}$ stretching band of acetophenone disappeared from the IR spectrum of the resulting mixture, indicating a direct reaction between $1-\left[\mathrm{K}([18] \mathrm{c}-6)(\mathrm{thf})_{0.5}\right]$ and the substrate. A ${ }^{1} \mathrm{H}$ NMR spectrum of the $1: 2$ reaction of 1$\left[\mathrm{K}([18] \mathrm{c}-6)(\text { thf })_{0.5}\right]$ and acetophenone in THF- $d_{8}$ led to disappearance of all signals of $1-\left[\mathrm{K}([18] \mathrm{c}-6)(\mathrm{thf})_{0.5}\right]$ in the spectrum. New signals appeared in the range of 81 to $-15 \mathrm{ppm}$ (see Figure S48). We conclude that complex 1-[K([18]c$\left.6)(\text { thf })_{0.5}\right]$ seems to be the precatalyst of the reaction.
Unfortunately, attempts to further characterize or isolate the resulting species have so far been unsuccessful.

\section{CONCLUSION}

This work shows that bis(aryl)iminoacenaphthene ligand BIAN is able to stabilize highly reduced iron complexes. 1$\left[\mathrm{K}([18] \mathrm{c}-6)(\mathrm{thf})_{0.5}\right], 2-\left[\mathrm{K}([18] \mathrm{c}-6)(\mathrm{thf})_{2}\right]$, and $3-[\mathrm{K}([18] \mathrm{c}-$ $6)($ thf $)]$ are accessible by reduction of $\alpha$-diimine iron(II) dibromide salts with potassium graphite or by ligand exchange using suitable low-valence ferrate precursors. The stability of these compounds is attributed to the redox-active nature of the BIAN ligand, which is present in the mono- or dianionic state in the molecular structures of these complexes. An additional cod ligand is present in $1-\left[\mathrm{K}([18] \mathrm{c}-6)(\text { thf })_{0.5}\right]$ and a dimerization product of norbornadiene is observed for 2$\left[\mathrm{K}([18] \mathrm{c}-6)(\mathrm{thf})_{2}\right]$, whereas compound $3-[\mathrm{K}([18] \mathrm{c}-6)(\mathrm{thf})]$ is a homoleptic complex of iron with two BIAN ligands. The electronic structures of the ferrate anions in these complexes were analyzed in detail by various experimental techniques $\left({ }^{1} \mathrm{H}\right.$ NMR and EPR spectroscopy, single-crystal X-ray crystallography, ${ }^{57} \mathrm{Fe}$ Mössbauer spectroscopy, SQUID magnetization measurement) as well as theoretical calculations at the DFT and CASSCF level. These data revealed an $\mathrm{Fe}(\mathrm{I})$ center with $S$ $=1 / 2$ for $1-\left[\mathrm{K}([18] \mathrm{c}-6)(\mathrm{thf})_{0.5}\right]$ and an $\mathrm{Fe}(\mathrm{III})$ center with rare intermediate spin $S=3 / 2$ for 2 - $\left[\mathrm{K}([18] \mathrm{c}-6)(\mathrm{thf})_{2}\right]$. For complex 3-[K([18]c-6)(thf)], the $S=3 / 2$ and $S=5 / 2$ states are close in energy with a small energy difference of $1.7 \mathrm{kcal}$ $\mathrm{mol}^{-1}$ in favor of the quartet state revealed by the CASSCF calculations.

As an initial test of their potential in homogeneous catalysis, the complexes were successfully applied in the catalytic hydroboration of carbonyl compounds with HBpin at ambient temperature. Gratifyingly, 1-[K([18]c-6)(thf $\left.)_{0.5}\right]$ and 2-[K$\left.([18] \mathrm{c}-6)(\text { thf })_{2}\right]$ were highly active. In particular complex 1$\left[\mathrm{K}([18] \mathrm{c}-6)(\mathrm{thf})_{0.5}\right]$ showed a high TOF $=220000 \mathrm{~h}^{-1}$ for the reduction of acetophenone and a broad functional group tolerance. These initial results are promising for the future application of highly reactive ferrate complexes as catalysts for a wider range of catalytic transformations.

\section{EXPERIMENTAL SECTION}

Materials. All experiments were performed under an atmosphere of dry argon (argon 4.6, Linde) using standard Schlenk techniques or 
an MBraun UniLab Glovebox. Solvents were dried and degassed with an MBraun SPS800 solvent-purification system. THF and diethyl ether were stored over molecular sieves ( $3 \AA$ ). $n$-Hexane was stored over a potassium mirror. 1,2-Dimethoxyethane was stirred over $\mathrm{K} /$ benzophenone, distilled, and stored over molecular sieves ( $3 \AA$ ). All chemicals were purchased from commercial suppliers and used as received, if not stated otherwise. $\left[\mathrm{Li}_{2}(\mathrm{dme})_{2}\left\{\mathrm{Fe}\left(\eta^{4}-\mathrm{cod}\right)_{2}\right\}\right],{ }^{53} \mathrm{KC}_{8},{ }^{54}$

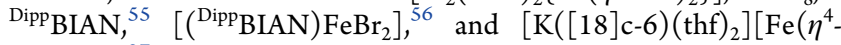
$\left.\left.\mathrm{C}_{14} \mathrm{H}_{10}\right)_{2}\right]^{27}$ were prepared according to literature procedures.

Instruments. CHN analyses were recorded by the analytical department of the University of Regensburg with a Micro Vario Cube (Elementar). ESI-MS spectra carried out by the analytical department of the University of Regensburg, Agilent Q-TOF 6549 UHD. Melting points were measured on samples in sealed capillaries on a Stuart SMP10 melting point apparatus. UV-vis spectra were recorded on an Ocean Optics Flame spectrometer (Varian Cary 50 Spectrophotometer) in a Quartz cuvette with a layer thickness of $1 \mathrm{~cm}$ at room temperature with a concentration of $1 \times 10^{-4}$ to $1 \times 10^{-6} \mathrm{M}$. ${ }^{1} \mathrm{H},{ }^{11} \mathrm{~B}$, ${ }^{13} \mathrm{C}\left\{{ }^{1} \mathrm{H}\right\}$, and ${ }^{19} \mathrm{~F}$ NMR spectra in solutions were recorded on Bruker Avance 300 and BrukerAvance 400 if not stated otherwise. Chemical shifts are given relative to solvents resonances in the tetramethylsilane $\left({ }^{1} \mathrm{H},{ }^{13} \mathrm{C}\right), \mathrm{BF}_{3} \cdot \mathrm{OEt}_{2}\left({ }^{11} \mathrm{~B}\right), \mathrm{CFCl}_{3}\left({ }^{19} \mathrm{~F}\right)$ scale. The following abbreviations have been used for multiplicities: $\mathrm{s}=$ singlet, $\mathrm{d}=$ doublet, $\mathrm{t}=$ triplet, $\mathrm{q}=$ quartet, sept $=$ septet, $\mathrm{m}=$ multiplet, $\mathrm{dd}=$ doublet of doublet, $\mathrm{dt}=$ doublet of triplet.

Cyclic Voltammetry. Cyclic voltammetry experiments were performed in a single-compartment cell inside a nitrogen-filled glovebox using a $\mathrm{CH}$ Instruments $\mathrm{CH} 1600 \mathrm{E}$ potentiostat. The cell was equipped with a platinum disc working electrode $(2 \mathrm{~mm}$ diameter) polished with $0.05 \mu \mathrm{m}$ alumina paste, a platinum wire counter electrode, and an $\mathrm{Ag} / \mathrm{AgNO}_{3}$ reference electrode. The supporting electrolyte, tetra- $n$-butylammonium hexafluorophosphate, was dried in vacuo at $110{ }^{\circ} \mathrm{C}$ for 3 days. All redox potentials are reported vs the ferrocenium/ferrocene $\left(\mathrm{Fc}^{+} / \mathrm{Fc}\right)$ couple.

EPR Spectroscopy. The experimental X-band EPR spectra was recorded on a Bruker EMX spectrometer (Bruker BioSpin Rheinstetten) equipped with a $\mathrm{He}$ temperature-control cryostat system (Oxford Instruments). The $g$ values were calculated with the ORCA software package ${ }^{57}$ at the $\mathrm{B}^{2} \mathrm{LYP}^{58} / \operatorname{def} 2-\mathrm{TZVP}^{59}$ level of theory. The spectra of 1-3 were analyzed and simulated using the W95EPR program of Prof. Frank Neese or EasySpin (easyspin.org). ${ }^{60}$

${ }^{57} \mathrm{Fe}$ Mössbauer Spectroscopy. ${ }^{57} \mathrm{Fe}$ Mössbauer spectra were recorded with a ${ }^{57} \mathrm{Co}$ source in a $\mathrm{Rh}$ matrix using an alternating constant acceleration Wissel Mössbauer spectrometer operated in the transmission mode and equipped with a Janis closed cycle helium cryostat. Isomer shifts are given relative to $\mathrm{Fe}$ metal at ambient temperature. Simulation of the experimental data was performed with the Mfit program using Lorentzian line doublets. ${ }^{61}$

Magnetic Susceptibility Measurements. Temperature-dependent magnetic susceptibility measurements were carried out with a Quantum-Design MPMS-XL-5 or with a MPMS3 SQUID magnetometer in the range from 295 (or 300 ) to $2.0 \mathrm{~K}$ at a magnetic field of $0.5 \mathrm{~T}$. The powdered samples were contained in a polypropylene or polycarbonate capsule and fixed in a nonmagnetic straw. Each raw data file for the measured magnetic moment was corrected for the diamagnetic contribution of the sample holder. The molar susceptibility data were corrected for the diamagnetic contribution. Experimental data for $2-\left[\mathrm{K}([18] \mathrm{c}-6)(\mathrm{thf})_{2}\right]$ and $3_{2}-[\mathrm{K}([18] \mathrm{c}-6)(\mathrm{thf})]$ were modeled with the julX program using a fitting procedure to the appropriate spin Hamiltonian for Zeeman splitting and zero-field splitting, eq 1.

$$
\hat{H}=\mu_{\mathrm{B}} \vec{B} \vec{S}+D\left[\hat{S}_{\mathrm{z}}^{2}-\frac{1}{3} S(S+1)\right]
$$

For $2-\left[\mathrm{K}([18] \mathrm{c}-6)(\text { thf })_{2}\right]$, the temperature-independent paramagnetism $\left(T I P=650 \times 10^{-6} \mathrm{~cm}^{3} \mathrm{~mol}^{-1}\right)$ was included.

Quantum Chemical Calculations. DFT and CASSCF calculations were performed using the ORCA program package. ${ }^{57}$ See the Supporting Information for further details.
Single-Crystal X-ray Crystallography. The single-crystal X-ray diffraction (XRD) data were recorded on an Agilent Super Nova diffractometer with an Atlas CCD detector. Microfocus $\mathrm{Cu} \mathrm{K}_{\alpha}$ radiation $(\lambda=1.54184 \AA)$ was used in each measurement. Empirical multiscan and analytical absorption corrections ${ }^{62}$ were applied to the data. The structures were solved with SHELXT ${ }^{63}$ and least-squares refinements on $F^{2}$ were carried out with SHELXL. ${ }^{64}$ The program package Olex $2^{65}$ was used. Crystal data for 1 -[ $[\mathrm{Li}(\mathrm{thf})], 2$ - $[\mathrm{K}([2.2 .2]$ cryptand $\left.)(\text { thf })_{3}\right]$, and $3-[\mathrm{K}([18] \mathrm{c}-6)($ thf $)]$ are given in section 4 below.

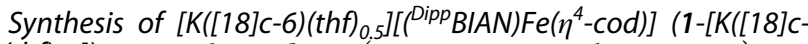
6) $\left.(\text { thf })_{0.5}\right]$ ). 1,5-Cyclooctadiene $(1.0 \mathrm{~mL}, 8.1 \mathrm{mmol}, 5.8$ equiv.) was added to a solution of $\left[\left({ }^{\text {Dipp }} \mathrm{BIAN}\right) \mathrm{FeBr}_{2}\right](1.0 \mathrm{~g}, 1.4 \mathrm{mmol}, 1.0$ equiv.) in $100 \mathrm{~mL}$ of THF. The solution was cooled to $-60{ }^{\circ} \mathrm{C}$ and $\mathrm{KC}_{8}(0.6 \mathrm{~g}, 4.4 \mathrm{mmol}, 3.15$ equiv.) was added in portions over $5 \mathrm{~min}$ and then slowly warmed to ambient temperature. Meanwhile, the solution turned yellow-brownish. After stirring overnight at ambient temperature, the resulting suspension was filtered and $[18] \mathrm{c}-6(0.37 \mathrm{~g}$, $1.4 \mathrm{mmol}, 1.0$ equiv.) in $15 \mathrm{~mL}$ of THF was added. The solution was concentrated to $80 \mathrm{~mL}$ of THF, layered with $80 \mathrm{~mL}$ of $n$-hexane and stored at $-10{ }^{\circ} \mathrm{C}$. Brown-green block shaped crystals were formed within a few days. $\left[\mathrm{K}([18] \mathrm{c}-6)(\mathrm{thf})_{0.5}\right]\left[\left({ }^{\text {Dipp }} \mathrm{BIAN}\right) \mathrm{Fe}\left(\eta^{4}\right.\right.$-cod $\left.)\right](1-$ $\left.\left[\mathrm{K}([18] \mathrm{c}-6)(\mathrm{thf})_{0.5}\right]\right)$ was isolated in $78 \%$ yield by decanting the solvent and drying the remaining crystalline solid in vacuo. Crystals suitable for single-crystal X-ray crystallography were obtained by recrystallization from THF $/ n$-hexane. Yield: $1.09 \mathrm{~g}(1.086 \mathrm{mmol}$, $78 \%)$. Melting point: $T>70{ }^{\circ} \mathrm{C}$ : decomposition to a black oil. ${ }^{1} \mathrm{H}$ NMR (400.13 MHz, $300 \mathrm{~K}$, THF- $\left.d_{8}\right): \delta$ [ppm]: 8.63 (m, Int 1), 4.77 (br s, Int 0.7), 4.35 (br s, Int 1), 3.51 (br s, overlap with THF- $d_{8}$, Int 12.5), 2.18 (br s, Int 3.3), 1.29 (br s, Int 1.7), 0.89 (br s, Int 1), 0.43 (br s, Int 2.5), - 16.2 (br s). EPR: Measured in ${ }^{\mathrm{Me}} \mathrm{THF}$ glass at $20 \mathrm{~K}$. Microwave frequency, $9.37466 \mathrm{GHz}$; modulation amplitude, $4.000 \mathrm{G}$; power, $0.6325 \mathrm{mV}$. The experimental spectrum could be fitted with the following parameters for an $S=1 / 2$ system on a nucleus with a nuclear spin of $0 . g_{1}=2.217, g_{2}=2.095, g_{3}=2.005, W_{1}=10, W_{2}=11$, and $W_{3}=13$. UV-vis (THF): $\lambda_{\max } / \mathrm{nm}\left(\varepsilon / \mathrm{L} \mathrm{mol}^{-1} \mathrm{~cm}^{-1}\right)=294$ (21 000), 408 (12 000), 697 (5000). CHN analysis found (calcd.) for $\mathrm{C}_{56} \mathrm{H}_{76} \mathrm{~N}_{2} \mathrm{KFeO}_{6} \cdot\left(\mathrm{C}_{4} \mathrm{H}_{8} \mathrm{O}\right)_{0.5}: \mathrm{C}, 69.78$ (69.37); H, 7.82 (8.03); N, 2.47 (2.79). Magnetic moment (Evans NMR method in THF- $d_{8}$ at $298 \mathrm{~K}): \mu_{\mathrm{eff}}=2.0(1) \mu_{\mathrm{B}} \cdot{ }^{57} \mathrm{Fe}$ Mößbauer spectrum: $\delta=0.23 \mathrm{~mm} \mathrm{~s}^{-1}$; $\left|\Delta E_{\mathrm{Q}}\right|=2.26 \mathrm{~mm} \mathrm{~s}^{-1}$.

Synthesis of [Li(thf)\{(Dipp BIAN)Fe( $\eta^{4}$-cod)\}] (1-[Li(thf)]). DippBIAN (75.2 $\mathrm{mg}, 0.15 \mathrm{mmol}, 1.5$ equiv.) was dissolved in $2 \mathrm{~mL}$ of THF and added dropwise as cooled $\left(-30{ }^{\circ} \mathrm{C}\right)$ solution to a $-30{ }^{\circ} \mathrm{C}$ cold solution of $\left[\mathrm{Li}_{2}(\mathrm{dme})_{2}\left\{\mathrm{Fe}\left(\eta^{4}-\mathrm{cod}\right)_{2}\right](46.7 \mathrm{mg}, 0.10 \mathrm{mmol}, 1.0\right.$ equiv.) in $2 \mathrm{~mL}$ of THF (Note: the dissolved ferrate contains some black particles). The olive-green solution turned dark brown and was warmed up to room temperature and stirred for $24 \mathrm{~h}$. The solvent was evaporated and residue extracted with $20 \mathrm{~mL} n$-hexane and filtered. Dark green-brown crystals were obtained by slow evaporation at room temperature and isolated by decanting the mother liquor and dried in vacuo. Yield: $40.8 \mathrm{mg}$ (0.055 mmol, 55\%). ${ }^{1} \mathrm{H}$ NMR (400.13 MHz, $\left.300 \mathrm{~K}, \mathrm{THF}-d_{8}\right): \delta$ [ppm]: 8.73 (br s), 7.20 (br s), 6.92 (br s), 6.07 (br s), 5.82 (br s), 5.50 (br s), 5.17-4.04 (m), 3.04-2.02 (m), 1.39$0.82(\mathrm{~m}), 0.41$ (br s), -0.98 (br s). CHN analysis found (calcd.) for $\mathrm{C}_{48} \mathrm{H}_{60} \mathrm{~N}_{2} \mathrm{LiFeO}$ : C, 76.57 (77.51); H, 7.88 (8.13); N, 3.55 (3.77).

Synthesis of $\left[K([18] \mathrm{c}-6)(\mathrm{thf})_{2}\right]\left[\left({ }^{D i p p} B I A N\right) \mathrm{Fe}\left(\mathrm{C}_{14} \mathrm{H}_{16}\right)\right] \quad(2-[K([18] \mathrm{c}-$

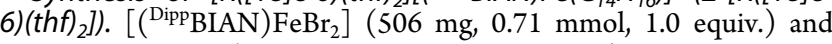
2,5-norbornadiene (1.4 mL, $13.8 \mathrm{mmol}, 19.4$ equiv.) were dissolved in $10 \mathrm{~mL}$ THF and cooled to $-70{ }^{\circ} \mathrm{C}$. Potassium graphite $\left(\mathrm{KC}_{8}, 304\right.$ $\mathrm{mg}, 2.25 \mathrm{mmol}, 3.2$ equiv.) was added in small portions. The color changed from orange-brown to deep green. The reaction mixture was warmed to room temperature and stirred overnight. The suspension was filtered and [18]c-6 $(187 \mathrm{mg}, 0.71 \mathrm{mmol}, 1.0$ equiv. $)$ in $5 \mathrm{~mL}$ of THF was added to the filtrate. The solution was reduced to $10 \mathrm{~mL}$ and layered with $25 \mathrm{~mL}$ of $n$-hexane. Dark-green crystals of $[\mathrm{K}([18] \mathrm{c}-$ 6) (thf $\left.)_{2}\right]\left[\left({ }^{\text {Dipp } B I A N}\right) \mathrm{Fe}\left(\mathrm{C}_{14} \mathrm{H}_{16}\right)\right] \quad\left(2-\left[\mathrm{K}([18] \mathrm{c}-6)(\text { thf })_{2}\right]\right)$ were formed within 1 day, isolated, and dried in vacuo. Recrystallization from $\mathrm{THF} / n$-hexane afforded crystals that were suitable for singlecrystal X-ray crystallography. The same reaction was conducted with 
[2.2.2] cryptand instead of $[18] \mathrm{c}-6$ to obtain crystals of the [2.2.2]cryptand complex 2 - $[\mathrm{K}([2.2 .2]$ cryptand $)]$ suitable for singlecrystal X-ray crystallography, which was not further characterized. Characterization data for 2 - $\left[\mathrm{K}([18] \mathrm{c}-6)(\text { thf })_{2}\right]$ : Yield: $0.7 \mathrm{~g}(0.59$ mmol, 83\%). Melting point: $T>200{ }^{\circ} \mathrm{C}$ : decomposition to a black oil. ${ }^{1} \mathrm{H}$ NMR (400.13 MHz, $300 \mathrm{~K}$, THF- $\left.d_{8}\right): \delta$ [ppm, Int = integral]: 69.2 (s, Int 1.5), 44.0 (s, Int 1), 30.5 (s, Int 1.2), 23.4 (s, Int 2), 14.6 (br s, Int 1.7), 14.4 (s, Int 2), 11.6 (s, Int 1.8), 4.9 (br s, Int 6), 4.8 (s, Int 3.5), 3.4 (s, Int 24, 18[c]-6), - 7.9 (m, Int 7.4), - 10.2 (s, Int 1,5 ), - 15.6 (s, Int 4.7), - 55.4 (br s, Int 0.06). EPR, measured in ${ }^{\mathrm{Me}} \mathrm{THF}$ glass at $20 \mathrm{~K}$; microwave frequency, $9.376835 \mathrm{GHz}$; modulation amplitude, $4.000 \mathrm{G}$; power, $0.6325 \mathrm{mV}$. The experimental spectrum of $2-\left[\mathrm{K}([18] \mathrm{c}-6)(\mathrm{thf})_{2}\right]$ can be fitted using the following parameters for a $S=3 / 2$ system. $g_{11}=2.25, g_{22}=2.25, g_{33}=1.90, D=$ $15 \mathrm{~cm}^{-1}, E=0.8 \mathrm{~cm}^{-1}, E / D=0.05$. UV-vis (THF): $\lambda_{\max } / \mathrm{nm}(\varepsilon / \mathrm{L}$ $\mathrm{mol}^{-1} \mathrm{~cm}^{-1}$ ) = 298 (22 000), 366 (13 500), 418 (8000), 740 (5000). $\mathrm{CHN}$ analysis found (calcd) for $\mathrm{C}_{62} \mathrm{H}_{76} \mathrm{~N}_{2} \mathrm{KFeO}_{6} \cdot\left(\mathrm{C}_{4} \mathrm{H}_{8} \mathrm{O}\right)_{2}: \mathrm{C}, 70.57$ (70.74); H, 7.84 (8.14); N, 2.13 (2.36). Magnetic moment (Evans NMR method in THF- $d_{8}$ at $\left.298 \mathrm{~K}\right), \mu_{\text {eff }}=3.9(1) \mu_{\mathrm{B}} ;{ }^{57} \mathrm{Fe}$ Mößbauer spectrum, $\delta=0.17 \mathrm{~mm} \mathrm{~s}^{-1} ;\left|\Delta E_{\mathrm{Q}}\right|=1.32 \mathrm{~mm} \mathrm{~s}^{-1}$.

Synthesis of $\left[K([18] c-6)(\text { thf })_{0.5}\right]\left[\left({ }^{\text {Dipp } B I A N}\right)_{2} \mathrm{Fe}\right](3-[K([18] \mathrm{c}-6)($ thf $)])$. $\left[\mathrm{K}([18] \mathrm{c}-6)(\mathrm{thf})_{2}\right]\left[\mathrm{Fe}\left(\eta^{4}-\mathrm{C}_{14} \mathrm{H}_{10}\right)_{2}\right](653 \mathrm{mg}, 0.76 \mathrm{mmol}, 1.0$ equiv. $)$ was dissolved in $60 \mathrm{~mL}$ of THF and DippBIAN $(761 \mathrm{mg}, 1.52 \mathrm{mmol}$, 2.0 equiv.) was added as solid to the solution. The color immediately changed from green to orange and the reaction mixture was stirred for $48 \mathrm{~h}$. The solvent was removed and the residue washed with $20 \mathrm{~mL}$ of $n$-hexane. The residue was extracted with $40 \mathrm{~mL}$ of THF and filtered. The solution was layered with $50 \mathrm{~mL}$ of $n$-hexane and stored at room temperature. After a few days, black crystals of $3-[\mathrm{K}([18] \mathrm{c}-6)(\mathrm{thf})]$ were isolated (490 mg, $0.35 \mathrm{mmol}, 46 \%)$ and dried in vacuo. Several samples were used for elemental analysis and spectroscopic characterization. These samples were obtained by two different methods: Samples $3_{1^{-}}[\mathrm{K}([18] \mathrm{c}-6)(\mathrm{thf})]$ : Samples labeled $3_{1^{-}}-[\mathrm{K}([18]-$ $\mathrm{c}-6)($ thf $)]$ were obtained by recrystallizing the crude product from $\mathrm{THF} / n$-hexane. Samples $3_{2}-[\mathrm{K}([18] \mathrm{c}-6)(\mathrm{thf})]$ : This sample was obtained by recrystallization of a sample $3_{1}-[K([18] \mathrm{c}-6)($ thf $)]$ from $\mathrm{THF} / n$-hexane. For both types of samples, crystals suitable for singlecrystal X-ray crystallography were obtained by diffusion of $n$-hexane into a concentrated THF solution. Several crystalline samples were examined by X-ray crystallography. All examined crystals had the same unit-cell parameters as reported in the Supporting Information (section 6.5.4). Yield of crude product, $490 \mathrm{mg}(0.35 \mathrm{mmol}, 46 \%)$; sample $3_{1^{-}}[\mathrm{K}([18] \mathrm{c}-6)(\mathrm{thf})], 163 \mathrm{mg}(0.11 \mathrm{mmol}, 15 \%)$; sample $3_{2^{-}}$ $[\mathrm{K}([18] \mathrm{c}-6)(\mathrm{thf})], 82 \mathrm{mg}(0.06 \mathrm{mmol}, 7 \%)$; melting point (sample $\left.3_{1}-[\mathrm{K}([18] \mathrm{c}-6)(\mathrm{thf})]\right), T>200{ }^{\circ} \mathrm{C}$; decomposition to a black oil. ${ }^{1} \mathrm{H}$ NMR $\left(400.13 \mathrm{MHz}, 300 \mathrm{~K}, \mathrm{THF}-d_{8}\right)$ : of sample $\mathbf{3}_{2}-[\mathrm{K}([18] \mathrm{c}-$ 6)(thf)]: $\delta$ [ppm]: 47.3 (s, Int: 1.0), 46.8 (br s, Int: 0.8), 7.1 (br s, Int: 3.5), 5.2 (s, Int: 1.5), 3.7 (br s, Int: 6.5), $3.58\left(\right.$ THF $\left._{\text {coordinated }}\right), 2.8$ (br s, Int: 1), 2.3 (br s, Int: 1), 1.74 (THF coordinated $), 1.29$ (n-hexane), 1.2 (br s, Int: 0.4$), 1.0$ (br s, Int: 0.5$), 0.89$ ( $n$-hexane), -3.4 (br s, Int: 2.6$),-3.4$ (s, Int: 2.8$),-11.0$ (br s, Int: 1.0), -17.3 (br s, Int: $2.8),-48.3$ (br s, Int: 0.4). EPR: Samples $3_{1}-[\mathrm{K}([18] \mathrm{c}-6)($ thf $)]$ and $3_{2}-[\mathrm{K}([18] \mathrm{c}-6)($ thf $)]$ were measured in a frozen ${ }^{\mathrm{Me}} \mathrm{THF}$ glass at $20 \mathrm{~K}$. Sample $3_{1}-[\mathrm{K}([18] \mathrm{c}-6)(\mathrm{thf})]$ : microwave frequency, $9.375682 \mathrm{GHz}$; modulation amplitude, $4.000 \mathrm{G}$; power, $0.6325 \mathrm{~mW}$. Sample $3_{1^{-}}$ $[\mathrm{K}([18] \mathrm{c}-6)(\mathrm{thf})]$ can be simulated as an $S=3 / 2$ species: $g_{11}=2.20$, $g_{22}=2.12, g_{33}=2.06, D=20 \mathrm{~cm}^{-1}, E=4.1 \mathrm{~cm}^{-1}, E / D=0.20$. Sample $3_{2}-[\mathrm{K}([18] \mathrm{c}-6)(\mathrm{thf})]:$ microwave frequency, $9.375682 \mathrm{GHz}$; modulation amplitude, $4.000 \mathrm{G}$; power, $0.6325 \mathrm{mV}$. Sample $3_{2}-[\mathrm{K}([18] \mathrm{c}-$ 6)(thf)] can be simulated as a $S=3 / 2$ species: $g_{11}=2.13, g_{22}=2.10$, $g_{33}=2.06, D=20 \mathrm{~cm}^{-1}, E=4.1 \mathrm{~cm}^{-1}, E / D=0.20$. UV-vis (THF): $\lambda_{\max } / \mathrm{nm}\left(\varepsilon / \mathrm{L} \mathrm{mol}^{-1} \mathrm{~cm}^{-1}\right)$. Sample $3_{1^{-}}[\mathrm{K}([18] \mathrm{c}-6)(\mathrm{thf})]: 360$ (20000, shoulder), 435 (7000), 505 (6500), 588 (3500). Sample $3_{2}-[\mathrm{K}([18] \mathrm{c}-6)(\mathrm{thf})]: 360$ (18000, shoulder), 435 (8500), 505 (8000), 588 (4000). CHN analysis found (calcd.) for $\mathrm{C}_{84} \mathrm{H}_{104} \mathrm{~N}_{4} \mathrm{KFeO}_{6} \cdot\left(\mathrm{C}_{4} \mathrm{H}_{8} \mathrm{O}\right)$. Results for sample $3_{1}-[\mathrm{K}([18] \mathrm{c}-6)($ thf $)]$ : C, 72.03 (73.77); H, 7.57 (7.88); N, 3.88 (3.91). Results for sample $3_{2}-[\mathrm{K}([18] \mathrm{c}-6)(\mathrm{thf})]: \mathrm{C}, 73.30(73.77) ; \mathrm{H}, 7.76(7.88) ; \mathrm{N}, 3.81$ (3.91). Magnetic moment (Evans NMR method in THF- $d_{8}$ at 298 $\mathrm{K})$ : sample $3_{1^{-}}[\mathrm{K}([18] \mathrm{c}-6)(\mathrm{thf})], \quad \mu_{\mathrm{eff}}=4.7(1) \mu_{\mathrm{B}}$; sample $\boldsymbol{3}_{2^{-}}$
$[\mathrm{K}([18] \mathrm{c}-6)($ thf $)], \mu_{\text {eff }}=4.7(1) \mu_{\mathrm{B}} \cdot{ }^{57} \mathrm{Fe}$ Mößbauer spectrum: sample $3_{2}-[\mathrm{K}([18] \mathrm{c}-6)(\mathrm{thf})], \delta=0.78 \mathrm{~mm} \mathrm{~s}^{-1}, \mid \Delta E_{\mathrm{Q}} \mathrm{I}=2.10 \mathrm{~mm} \mathrm{~s}^{-1}$; sample $3_{1}-[\mathrm{K}([18] \mathrm{c}-6)(\mathrm{thf})], \delta=0.76 \mathrm{~mm} \mathrm{~s}^{-1}, \mid \Delta E_{\mathrm{Q}} \mathrm{I}=1.63 \mathrm{~mm} \mathrm{~s}^{-1}$. A fitting procedure revealed that the simulated spectrum can be divided into two subunits (sub1 and sub2) with isomer shifts of $\delta=0.75 \mathrm{~mm} \mathrm{~s}^{-1}$ (share of $75 \%$, sub1) and $\delta=0.78 \mathrm{~mm} \mathrm{~s}^{-1}$ (share of $25 \%$, sub2). The corresponding quadrupole splitting values are $\left|\Delta E_{\mathrm{Q}}\right|=1.60 \mathrm{~mm} \mathrm{~s}^{-1}$ (sub1) and $\left|\Delta E_{\mathrm{Q}}\right|=2.17 \mathrm{~mm} \mathrm{~s}^{-1}$ (sub2).

\section{ASSOCIATED CONTENT}

\section{SI Supporting Information}

The Supporting Information is available free of charge at https://pubs.acs.org/doi/10.1021/acs.inorgchem.0c02606.

Single-crystal X-ray crystallography; ${ }^{1} \mathrm{H}$ NMR, EPR, ${ }^{57} \mathrm{Fe}$ Mößbauer, and UV-vis spectra; cyclic voltammetry; computational details; catalytic hydroboration (PDF)

\section{Accession Codes}

CCDC 2026690-2026692 contain the supplementary crystallographic data for this paper. These data can be obtained free of charge via www.ccdc.cam.ac.uk/data_request/cif, or by emailing data_request@ccdc.cam.ac.uk, or by contacting The Cambridge Crystallographic Data Centre, 12 Union Road, Cambridge CB2 1EZ, UK; fax: +44 1223336033.

\section{AUTHOR INFORMATION}

\section{Corresponding Author}

Robert Wolf - Institute of Inorganic Chemistry, University of Regensburg, 93040 Regensburg, Germany; ○ orcid.org/00000003-4066-6483; Email: robert.wolf@ur.de

\section{Authors}

Thomas M. Maier - Institute of Inorganic Chemistry, University of Regensburg, 93040 Regensburg, Germany

Martin Gawron - Institute of Inorganic Chemistry, University of Regensburg, 93040 Regensburg, Germany

Peter Coburger - Institute of Inorganic Chemistry, University of Regensburg, 93040 Regensburg, Germany

Michael Bodensteiner - Institute of Inorganic Chemistry, University of Regensburg, 93040 Regensburg, Germany

Nicolaas P. van Leest - van 't Hoff Institute for Molecular Sciences (HIMS), University of Amsterdam, 1098 XH Amsterdam, The Netherlands

Bas de Bruin - van 't Hoff Institute for Molecular Sciences (HIMS), University of Amsterdam, 1098 XH Amsterdam, The Netherlands; (1) orcid.org/0000-0002-3482-7669

Serhiy Demeshko - Institute of Inorganic Chemistry, University of Göttingen, 37077 Göttingen, Germany

Franc Meyer - Institute of Inorganic Chemistry and International Center for Advanced Studies of Energy Conversion (ICASEC), University of Göttingen, 37077 Göttingen,

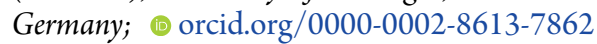

Complete contact information is available at: https://pubs.acs.org/10.1021/acs.inorgchem.0c02606

\section{Author Contributions}

T.M.M. performed the experimental work and wrote the manuscript. M.G. assisted with the synthetic work. P.C. assisted with the quantum-chemical calculations. N.P.v.L. and B.d.B. recorded and analyzed EPR data. M.B. helped with the refinement of single-crystal X-ray crystallography data. S.D. and F.M. conducted and interpreted ${ }^{57} \mathrm{Fe}$ Mössbauer spectra and SQUID magnetization measurements. R.W. supervised and directed the project. 


\section{Funding}

European Reseach Council (ERC GoG 772299) Fonds der Chemischen Industrie (fellowship to T.M.M.)

\section{Notes}

The authors declare no competing financial interest.

\section{ACKNOWLEDGMENTS}

Financial support by the European Research Council (ERC CoG 772299) and the Fonds der Chemischen Industrie (fellowship to T.M.M.) is gratefully acknowledged. We thank Julia Märsch (University of Regensburg) and Andreas Rösch (University of Regensburg) for experimental assistance, and Dr. Daniel J. Scott (Universität Regensburg) for assistance with manuscript preparation. Prof. Robert Kretschmer (University of Jena) is thanked for providing access to a ReactIR device.

\section{REFERENCES}

(1) Crabtree, R. H. An Organometallic Future in Green and Energy Chemistry. Organometallics 2011, 30, 17-19.

(2) Bolm, C.; Legros, J.; Le Paih, J.; Zani, L. Iron-Catalyzed Reactions in Organic Synthesis. Chem. Rev. 2004, 104, 6217-6254. Bauer, I.; Knölker, H.-J. Iron Catalysis in Organic Synthesis. Chem. Rev. 2015, 115, 3170-3387.

(3) Wei, D.; Darcel, C. Iron Catalysis in Reduction and Hydrometalation Reactions. Chem. Rev. 2019, 119, 2550-2610.

(4) (a) Chirik, P. J.; Wieghardt, K. Chemistry. Radical ligands confer nobility on base-metal catalysts. Science 2010, 327, 794-795. (b) Praneeth, V. K. K.; Ringenberg, M. R.; Ward, T. R. Redox-active ligands in Catalysis. Angew. Chem., Int. Ed. 2012, 51, 10228-10234; Angew. Chem. 2012, 124, 10374-10380. (c) Luca, O. R.; Crabtree, R. H. Redox-active ligands in Catalysis. Chem. Soc. Rev. 2013, 42, 14401459.

(5) van der Vlugt, J. I. Radical-Type Reactivity and Catalysis by Single-Electron Transfer to or from Redox-Active Ligands. Chem. Eur. J. 2019, 25, 2651-2662.

(6) Selected examples for Ni: (a) Léonard, N. G.; Chirik, P. J. AirStable $\alpha$-Diimine Nickel Precatalysts for the Hydrogenation of Hindered, Unactivated Alkenes. ACS Catal. 2018, 8, 342-348. (b) Leonard, N. G.; Yruegas, S.; Ho, S. C.; Sattler, A.; Bezdek, M. J.; Chirik, P. J. Synthesis of Cationic, Dimeric $\alpha$-Diimine Nickel Hydride Complexes and Relevance to the Polymerization of Olefins. Organometallics 2020, 39, 2630-2635.

(7) Selected examples for Co: (a) Palmer, W. N.; Diao, T.; Pappas, I.; Chirik, P. J. High-Activity Cobalt Catalysts for Alkene Hydroboration with Electronically Responsive Terpyridine and $\alpha$-Diimine Ligands. ACS Catal. 2015, 5, 622. (b) Maier, T. M.; Sandl, S.; Shenderovich, I. G.; Jacobi von Wangelin, A.; Weigand, J. J.; Wolf, R. Amine-Borane Dehydrogenation and Transfer Hydrogenation Catalyzed by $\alpha$-Diimine Cobaltates. Chem. - Eur. J. 2019, 25, 238-245. (c) Sandl, S.; Maier, T. M.; van Leest, N. P.; Kröncke, S.; Chakraborty, U.; Demeshko, S.; Koszinowski, K.; de Bruin, B.; Meyer, F.; Bodensteiner, M.; Herrmann, C.; Wolf, R.; Jacobi von Wangelin, A. Cobalt-Catalyzed Hydrogenations via Olefin Cobaltate and Hydride Intermediates. ACS Catal. 2019, 9, 7596-7606.

(8) Le Floch, P.; Knoch, F.; Kremer, F.; Mathey, F.; Scholz, J.; Scholz, W.; Thiele, K.-H.; Zenneck, U. [(Arene)(Diene)Fe] and [(Arene)(Diazadiene)Fe] Complexes: Preparation, Reactivity, and Catalytic Properties. Eur. J. Inorg. Chem. 1998, 1998, 119-126.

(9) (a) Bart, S. C.; Hawrelak, E. J.; Lobkovsky, E.; Chirik, P. J. LowValent $\alpha$-Diimine Iron Complexes for Catalytic Olefin Hydrogenation. Organometallics 2005, 24, 5518-5527. (b) Schmidt, V. A.; Kennedy, C. R.; Bezdek, M. J.; Chirik, P. J. Selective 1,4Hydrovinylation of 1,3-Dienes with Unactivated Olefins Enabled by Iron Diimine Catalysts. J. Am. Chem. Soc. 2018, 140, 3443-3453.
(10) Janes, T.; Rawson, J. M.; Song, D. Syntheses and structures of $\mathrm{Li}, \mathrm{Fe}$, and $\mathrm{Mo}$ derivatives of $\mathrm{N}, \mathrm{N}^{\prime}$-bis(2,6-diisopropylphenyl)-ophenylenediamine. Dalton Trans. 2013, 42, 10640-10648.

(11) Wekesa, F. S.; Arias-Ugarte, R.; Kong, L.; Sumner, Z.; McGovern, G. P.; Findlater, M. Iron-Catalyzed Hydrosilylation of Aldehydes and Ketones under Solvent-Free Conditions. Organometallics 2015, 34, 5051-5056.

(12) Brown, L. A.; Wekesa, F. S.; Unruh, D. K.; Findlater, M.; Long, B. K. BIAN-Fe $\left(\eta^{6}-\mathrm{C}_{6} \mathrm{H}_{6}\right)$ : Synthesis, characterization, and 1-lactide polymerization. J. Polym. Sci., Part A: Polym. Chem. 2017, 55, 28242830.

(13) (a) Matei, I.; Lixandru, T. Bul. Inst. Politeh. Iasi 1967, 13, 245. (b) Dvolaitzky, M. C. R. Acad. Sci. Prais, Ser. C 1969, 268, 1811.

(14) (a) van Asselt, R.; Elsevier, J. C. Homogeneous catalytic hydrogenation of alkenes by zero-valent palladium complexes of cisfixed dinitrogen ligands. J. Mol. Catal. 1991, 65, L13-L19. (b) van Asselt, R.; Gielens, E. E. C. G.; Rülke, R. E.; Elsevier, C. J. Isolation of alkyl- and acyl-palladium complexes containing rigid bidentate nitrogen ligands by stepwise successive insertion of $\mathrm{CO}$ and alkenes. J. Chem. Soc., Chem. Commun. 1993, 102, 1203-1205. (c) van Asselt, R.; Gielens, E. E. C. G.; Rulke, R. E.; Vrieze, K.; Elsevier, C. J. Rigid bidentate nitrogen ligands in organometallic chemistry and homogeneous catalysis. 3. Insertion of carbon monoxide and alkenes into palladium-carbon bonds of complexes containing rigid bidentate nitrogen ligands: the first example of isolated complexes in stepwise successive insertion reactions on the way to polyketones. J. Am. Chem. Soc. 1994, 116, 977-985.

(15) Fedushkin, I. L.; Skatova, A. A.; Chudakova, V. A.; Fukin, G. K. Four-step reduction of dpp-Bian with sodium metal: crystal structures of the sodium salts of the mono-, di-, tri- and tetraanions of dpp-Bian. Angew. Chem., Int. Ed. 2003, 42, 3294-3298; Angew. Chem. 2003, $115,3416-3420$.

(16) Villa, M.; Miesel, D.; Hildebrandt, A.; Ragaini, F.; Schaarschmidt, D.; Jacobi von Wangelin, A. Synthesis and Catalysis of Redox-Active Bis(imino)acenaphthene (BIAN) Iron Complexes. Chem CatChem 2017, 9, 3203-3209.

(17) Lee, H.; Campbell, M. G.; Hernández Sánchez, R.; Börgel, J.; Raynaud, J.; Parker, S. E.; Ritter, T. Mechanistic Insight Into HighSpin Iron(I)-Catalyzed Butadiene Dimerization. Organometallics 2016, 35, 2923-2929.

(18) Larson, P. J.; Wekesa, F. S.; Singh, A.; Smith, C. R.; Rajput, A.; McGovern, G. P.; Unruh, D. K.; Cozzolino, A. F.; Findlater, M. Synthesis, characterization, electrochemical properties and theoretical calculations of (BIAN) iron complexes. Polyhedron 2019, 159, 365374.

(19) Bart, S. C.; Hawrelak, E. J.; Schmisseur, A. K.; Lobkovsky, E.; Chirik, P. J. Synthesis, Reactivity, and Solid State Structures of FourCoordinate Iron(II) and Manganese(II) Alkyl Complexes. Organometallics 2004, 23, 237-246.

(20) (a) Lichtenberg, C.; Adelhardt, M.; Gianetti, T. L.; Meyer, K.; de Bruin, B.; Grutzmacher, H. Low-Valent Iron Mono-Diazadiene Compounds: Electronic Structure and Catalytic Application. ACS Catal. 2015, 5, 6230-6240. (b) Lichtenberg, C.; Viciu, L.; Adelhardt, M.; Sutter, J.; Meyer, K.; de Bruin, B.; Grutzmacher, H. Low-valent iron(I) amido olefin complexes as promotors for dehydrogenation reactions. Angew. Chem., Int. Ed. 2015, 54, 5766-5771; Angew. Chem. 2015, 127, 5858-5863.

(21) tom Dieck, H.; Bruder, H. Bis(diazadiene)iron complexes. J. Chem. Soc., Chem. Commun. 1977, 24-25.

(22) Walther, D.; Kreisel, G.; Krimse, R. Wechselwirkungen zwischen Hetero-N-Systemen und Zentralmetallen niedriger Oxydationsstufen. Koordinationschemie des Benzildianils, eines extrem aciden 1,4-Diazabutadiens. Z. Anorg. Allg. Chem. 1982, 487, 149-160.

(23) Muresan, N.; Lu, C. C.; Ghosh, M.; Peters, J. C.; Abe, M.; Henling, L. M.; Weyhermöller, T.; Bill, E.; Wieghardt, K. Bis $(\alpha-$ diimine)iron complexes: electronic structure determination by spectroscopy and broken symmetry density functional theoretical calculations. Inorg. Chem. 2008, 47, 4579-4590. 
(24) Fedushkin, I. L.; Skatova, A. A.; Khvoinova, N. M.; Lukoyanov, A. N.; Fukin, G. K.; Ketkov, S. Y.; Maslov, M. O.; Bogomyakov, A. S.; Makarov, V. M. New high-spin iron complexes based on bis(imino)acenaphthenes (BIAN): synthesis, structure, and magnetic properties. Russ. Chem. Bull. 2013, 62, 2122-2131.

(25) (a) Pelties, S.; Maier, T.; Herrmann, D.; de Bruin, B.; Rebreyend, C.; Gartner, S.; Shenderovich, I. G.; Wolf, R. Selective $\mathrm{P}_{4}$ Activation by a Highly Reduced Cobaltate: Synthesis of Dicobalt Tetraphosphido Complexes. Chem. - Eur. J. 2017, 23, 6094-6102.

(26) Jonas, K.; Schieferstein, L.; Krüger, C.; Tsay, Y.-H. Tetrakis(ethylene)irondilithium and $\operatorname{Bis}\left(\eta^{4}-1,5\right.$-cyclooctadiene)irondilithium. Angew. Chem., Int. Ed. Engl. 1979, 18, 550-551; Angew. Chem. 1979, 91, 590-591.

(27) (a) Brennessel, W. W.; Jilek, R. E.; Ellis, J. E. Bis(1,2,3,4- $\eta^{4}$ anthracene)ferrate (1-): a paramagnetic homoleptic polyarene transition-metal anion. Angew. Chem., Int. Ed. 2007, 46, 61326136; Angew. Chem. 2007, 119, 6244-6248. (b) Büschelberger, P.; Rödl, C.; Chakraborty, U.; Wolf, R. \{(18-crown-6)bis(tetrahydrofurane) potassium $\}\left\{\right.$ bis $\left(1,2,3,4-\eta^{4}\right.$-anthracene) metallates $\}$ of cobalt $(-\mathrm{I})$ and iron $(-\mathrm{I}),\left\{\mathrm{K}(18\right.$-crown- 6$\left.)(\text { thf })_{2}\right\}\left\{\mathrm{M}\left(\eta^{4}\right.\right.$ $\left.\left.\mathrm{C}_{14} \mathrm{H}_{10}\right)_{2}\right\}, \mathrm{M}=\mathrm{Co}$, Fe. Inorganic Synthesis; Wiley, 2018; Vol. 37, Chapter 4.8, pp 76-84.

(28) (a) Khusniyarov, M. M.; Weyhermuller, T.; Bill, E.; Wieghardt, K. Reversible Electron Transfer Coupled to Spin Crossover in an Iron Coordination Salt in the Solid State. Angew. Chem., Int. Ed. 2008, 47, 1228-1231; Angew. Chem. 2008, 120, 1248-1251. (b) Khusniyarov, M. M.; Bill, E.; Weyhermüller, T.; Bothe, E.; Harms, K.; Sundermeyer, J.; Wieghardt, K. Characterization of Three Members of the ElectronTransfer Series $\left[\mathrm{Fe}(\mathrm{pda})_{2}\right]^{n}(n=2-, 1-, 0)$ by Spectroscopy and Density Functional Theoretical Calculations $[\mathrm{pda}=$ Redox Noninnocent Derivatives of $N, N$ '-Bis(pentafluorophenyl)-ophenylenediamide(2-, 1.-, 0)]. Chem. - Eur. J. 2008, 14, 76087622. (c) Khusniyarov, M. M.; Harms, K.; Burghaus, O.; Sundermeyer, J.; Sarkar, B.; Kaim, W.; van Slageren, J.; Duboc, C.; Fiedler, J. A series of metal complexes with the non-innocent $N, N^{\prime}$ bis(pentafluorophenyl)-o-phenylenediamido ligand: twisted geometry for tuning the electronic structure. Dalton Trans. 2008, 1355-1365.

(29) Sun, H.; Burlakov, V. V.; Spannenberg, A.; Baumann, W.; Arndt, P.; Rosenthal, U. Synthesis and Structural Investigation of Stable Zirconacyclopentanes Which Bear Additional Functional Groups. Organometallics 2001, 20, 5472-5477.

(30) Bezman, S. A.; Bird, P. H.; Fraser, A. R.; Osborn, J. A. Metallacyclic complexes of iridium. Inorg. Chem. 1980, 19, 37553763.

(31) Betoré, M. P.; Casado, M. A.; García-Orduña, P.; Lahoz, F. J.; Polo, V.; Oro, L. A. 2,5-Norbornadiene C-C Coupling Reactions Mediated by Iridium Complexes. Eur. J. Inorg. Chem. 2016, 2016, 3489-3499.

(32) Sgro, M. J.; Stephan, D. W. Synthesis and exchange reactions of Ni-diimine-COD, acetylene and olefin complexes. Dalton Trans. 2010, 39, 5786-5794.

(33) Stephens, P. J.; Devlin, F. J.; Chabalowski, C. F.; Frisch, M. J. $\mathrm{Ab}$ Initio Calculation of Vibrational Absorption and Circular Dichroism Spectra Using Density Functional Force Fields. J. Phys. Chem. 1994, 98, 11623-11627.

(34) Weigend, F.; Ahlrichs, R. Balanced basis sets of split valence, triple zeta valence and quadruple zeta valence quality for $\mathrm{H}$ to $\mathrm{Rn}$ : Design and assessment of accuracy. Phys. Chem. Chem. Phys. 2005, 7, 3297-3305.

(35) Bowman, A. C.; Tondreau, A. M.; Lobkovsky, E.; Margulieux, G. W.; Chirik, P. J. Synthesis and Electronic Structure Diversity of Pyridine(diamine)iron Tetrazene Complexes. Inorg. Chem. 2018, 57, 9634-9643.

(36) Cowley, R. E.; Bill, E.; Neese, F.; Brennessel, W. W.; Holland, P. L. Inorg. Chem. 2009, 48, 4828-4836.

(37) Evans, D. F. The determination of the paramagnetic susceptibility of substances in solution by nuclear magnetic resonance. J. Chem. Soc. 1959, 2003.
(38) Swart, M.; Ehlers, A. W.; Lammertsma, K. Performance of the OPBE exchange-correlation functional. Mol. Phys. 2004, 102, 24672474.

(39) (a) Grimme, S.; Antony, J.; Ehrlich, S.; Krieg, H. A consistent and accurate $a b$ initio parametrization of density functional dispersion correction (DFT-D) for the 94 elements H-Pu. J. Chem. Phys. 2010, 132, 154104. (b) Grimme, S.; Ehrlich, S.; Goerigk, L. Effect of the damping function in dispersion corrected density functional theory. $J$. Comput. Chem. 2011, 32, 1456-1465.

(40) Morris Bullock, R. Catalysis without Precious Metals; Wiley$\mathrm{VCH}, 2010$.

(41) Metal-Organic Compounds; Sittig, M., Ed.; Advances in Chemistry Series; American Chemical Society: 1959; Vol. 23.

(42) Chong, C. C.; Kinjo, R. Catalytic Hydroboration of Carbonyl Derivatives, Imines, and Carbon Dioxide. ACS Catal. 2015, 5, 32383259.

(43) (a) Zhang, G.; Zeng, H.; Wu, J.; Yin, Z.; Zheng, S.; Fettinger, J. C. Highly Selective Hydroboration of Alkenes, Ketones and Aldehydes Catalyzed by a Well-Defined Manganese Complex. Angew. Chem., Int. Ed. 2016, 55, 14369-14372; Angew. Chem. 2016, 128, 14581-14584. (b) Vasilenko, V.; Blasius, C. K.; Wadepohl, H.; Gade, L. H. Mechanism-Based Enantiodivergence in Manganese Reduction Catalysis: A Chiral Pincer Complex for the Highly Enantioselective Hydroboration of Ketones. Angew. Chem., Int. Ed. 2017, 56, 8393-8397; Angew. Chem. 2017, 129, 8513-8517. (c) Vasilenko, V.; Blasius, C. K.; Gade, L. H. One-Pot Sequential Kinetic Profiling of a Highly Reactive Manganese Catalyst for Ketone Hydroboration: Leveraging $\sigma$-Bond Metathesis via Alkoxide Exchange Steps. J. Am. Chem. Soc. 2018, 140, 9244-9254.

(44) (a) Guo, J.; Chen, J.; Lu, Z. Cobalt-catalyzed asymmetric hydroboration of aryl ketones with pinacolborane. Chem. Commun. 2015, 51, 5725-5727. (b) Docherty, J. H.; Peng, J.; Dominey, A. P.; Thomas, S. P. Activation and discovery of earth-abundant metal catalysts using sodium tert-butoxide. Nat. Chem. 2017, 9, 595-600. (c) Tamang, S. R.; Bedi, D.; Shafiei-Haghighi, S.; Smith, C. R.; Crawford, C.; Findlater, M. Cobalt-Catalyzed Hydroboration of Alkenes, Aldehydes, and Ketones. Org. Lett. 2018, 20, 6695-6700. (d) Wu, J.; Zeng, H.; Cheng, J.; Zheng, S.; Golen, J. A.; Manke, D. R.; Zhang, G. Cobalt(II) Coordination Polymer as a Precatalyst for Selective Hydroboration of Aldehydes, Ketones, and Imines. J. Org. Chem. 2018, 83, 9442-9448.

(45) King, A. E.; Stieber, S. C. E.; Henson, N. J.; Kozimor, S. A.; Scott, B. L.; Smythe, N. C.; Sutton, A. D.; Gordon, J. C. $\mathrm{Ni}($ bpy)(cod): A Convenient Entryway into the Efficient Hydroboration of Ketones, Aldehydes, and Imines. Eur. J. Inorg. Chem. 2016, 2016, 1635-1640.

(46) Tamang, S. R.; Findlater, M. Iron Catalyzed Hydroboration of Aldehydes and Ketones. J. Org. Chem. 2017, 82, 12857-12862.

(47) Bai, T.; Janes, T.; Song, D. Homoleptic iron(II) and cobalt(II) bis(phosphoranimide) complexes for the selective hydrofunctionalization of unsaturated molecules. Dalton Trans. 2017, 46, 12408-12412.

(48) Liu, J.; Zhang, A.; Song, H.; Tong, Q.; Tung, C.-H.; Wang, W. Iron(II) hydrides bearing a tetradentate PSNP ligand. Chin. Chem. Lett. 2018, 29, 949-953.

(49) Das, U. K.; Higman, C. S.; Gabidullin, B.; Hein, J. E.; Baker, R T. Efficient and Selective Iron-Complex-Catalyzed Hydroboration of Aldehydes. ACS Catal. 2018, 8, 1076-1081.

(50) (a) Khoo, S.; Cao, J.; Ng, F.; So, C.-W. Synthesis of a BaseStabilized Silicon(I)-Iron(II) Complex for Hydroboration of Carbonyl Compounds. Inorg. Chem. 2018, 57, 12452-12455. (b) Qi, X.; Zheng, T.; Zhou, J.; Dong, Y.; Zuo, X.; Li, X.; Sun, H.; Fuhr, O.; Fenske, D. Synthesis and Catalytic Activity of Iron Hydride Ligated with Bidentate N-Heterocyclic Silylenes for Hydroboration of Carbonyl Compounds. Organometallics 2019, 38, 268-277.

(51) Blasius, C. K.; Vasilenko, V.; Gade, L. H. Ultrafast IronCatalyzed Reduction of Functionalized Ketones: Highly Enantioselective Synthesis of Halohydrines, Oxaheterocycles, and Aminoalcohols. Angew. Chem., Int. Ed. 2018, 57, 10231-10235; Angew. Chem. 2018, 130, 10388-10392. 
(52) (a) Crabtree, R. H. Resolving heterogeneity problems and impurity artifacts in operationally homogeneous transition metal catalysts. Chem. Rev. 2012, 112, 1536-1554. (b) Artero, V.; Fontecave, M. Solar fuels generation and molecular systems: is it homogeneous or heterogeneous catalysis? Chem. Soc. Rev. 2013, 42, 2338-2356. Gartner, D.; Welther, A.; Rad, B. R.; Wolf, R.; Jacobi von Wangelin, A. Heteroatom-Free Arene-Cobalt and Arene-Iron Catalysts for Hydrogenations. Angew. Chem., Int. Ed. 2014, 53, 3722-3726; Angew. Chem. 2014, 126, 3796-3800. Sonnenberg, J. F.; Morris, R. H. Distinguishing homogeneous from nanoparticle asymmetric iron catalysis. Catal. Sci. Technol. 2014, 4, 3426-3438.

(53) Fürstner, A.; Martin, R.; Krause, H.; Seidel, G.; Goddard, R.; Lehmann, C. W. Preparation, Structure, and Reactivity of Nonstabilized Organoiron Compounds. Implications for Iron-Catalyzed Cross Coupling Reactions. J. Am. Chem. Soc. 2008, 130, 8773-8787.

(54) Maier, T. M.; Coburger, P.; van Leest, N. P.; Hey-Hawkins, E.; Wolf, R. Direct synthesis of an anionic 13-vertex closo-cobaltacarborane cluster. Dalton Trans. 2019, 48, 15772-15777.

(55) Paulovicova, A.; El-Ayaan, U.; Shibayama, K.; Morita, T.; Fukuda, Y. Mixed-Ligand Copper(II) Complexes with the Rigid Bidentate $\operatorname{Bis}(\mathrm{N}$-arylimino)acenaphthene Ligand: Synthesis, Spectroscopic-, and X-ray Structural Characterization. Eur. J. Inorg. Chem. 2001, 2001, 2641-2646.

(56) Supej, M. J.; Volkov, A.; Darko, L.; West, R. A.; Darmon, J. M.; Schulz, C. E.; Wheeler, K. A.; Hoyt, H. M. Aryl-substituted BIAN complexes of iron dibromide: Synthesis, X-ray and electronic structure, and catalytic hydrosilylation activity. Polyhedron 2016, 114, 403-414.

(57) Neese, F. Software update: the ORCA program system, version 4.0, Interdiscip. Wiley Interdiscip. Rev.: Comput. Mol. Sci. 2012, 2, 7378 .

(58) Stephens, P. J.; Devlin, F. J.; Chabalowski, C. F.; Frisch, M. J. $\mathrm{Ab}$ Initio Calculation of Vibrational Absorption and Circular Dichroism Spectra Using Density Functional Force Fields. J. Phys. Chem. 1994, 98, 11623-11627.

(59) Weigend, F.; Ahlrichs, R. Balanced basis sets of split valence, triple zeta valence and quadruple zeta valence quality for $\mathrm{H}$ to $\mathrm{Rn}$ : Design and assessment of accuracy. Phys. Chem. Chem. Phys. 2005, 7, 3297-3305.

(60) Stoll, S.; Schweiger, A. EasySpin, a comprehensive software package for spectral simulation and analysis in EPR. J. Magn. Reson. 2006, 178, 42-55.

(61) Bill, E. Mfit Max-Planck Institute for Chemical Energy Conversion: Mühlheim/Ruhr, Germany.

(62) Clark, R. C.; Reid, J. S. The analytical calculation of absorption in multifaceted crystals. Acta Crystallogr., Sect. A: Found. Crystallogr. 1995, 51, 887-897. (b) CrysAlisPRo, Ver. 40_64.18; Agilent Technologies Inc.: Oxford, U.K..

(63) Sheldrick, G. M. SHELXT - Integrated space-group and crystal-structure determination. Acta Crystallogr., Sect. A: Found. Adv. 2015, 71, 3-8.

(64) Sheldrick, G. M. Crystal structure refinement with SHELXL. Acta Crystallogr., Sect. C: Struct. Chem. 2015, 71, 3-8.

(65) Dolomanov, O. V.; Bourhis, L. J.; Gildea, R. J.; Howard, J. A. K.; Puschmann, H. OLEX2: a complete structure solution, refinement and analysis program. J. Appl. Crystallogr. 2009, 42, 339-341. 